\title{
Functional Movement Screen Composite Scores for Collegiate Field Club Sport Athletes at One University
}

Daniel Camillone

Follow this and additional works at: https://researchrepository.wvu.edu/etd

\section{Recommended Citation}

Camillone, Daniel, "Functional Movement Screen Composite Scores for Collegiate Field Club Sport Athletes at One University" (2018). Graduate Theses, Dissertations, and Problem Reports. 5304. https://researchrepository.wvu.edu/etd/5304

This Thesis is protected by copyright and/or related rights. It has been brought to you by the The Research Repository @ WVU with permission from the rights-holder(s). You are free to use this Thesis in any way that is permitted by the copyright and related rights legislation that applies to your use. For other uses you must obtain permission from the rights-holder(s) directly, unless additional rights are indicated by a Creative Commons license in the record and/ or on the work itself. This Thesis has been accepted for inclusion in WVU Graduate Theses, Dissertations, and Problem Reports collection by an authorized administrator of The Research Repository @ WVU. For more information, please contact researchrepository@mail.wvu.edu. 
Functional Movement Screen Composite Scores For Collegiate Field Club Sport Athletes at One University

Daniel Camillone, ATC, CSCS

\author{
Thesis Submitted to the \\ College of Physical Activity and Sport Sciences \\ at West Virginia University \\ in partial fulfillment of the requirements for the degree of \\ Master of Science in \\ Athletic Training
}

Michelle A. Sandrey, PhD, ATC, Chair

Jean L. McCrory, PhD

Patricia Riley, MS, ATC, PES

Department of Sport Sciences

Morgantown, West Virginia

2018

Keywords: functional movement screen, composite score, club sports

Copyright 2018 Daniel Camillone 


\begin{abstract}
Functional Movement Screen Composite Scores For Collegiate Field Club Sport Athletes at One University
\end{abstract}

\title{
Daniel Camillone, ATC, CSCS
}

Context: Functional screening tools to detect musculoskeletal asymmetries and limitations present in functional movement patterns are available to use for the athletic population. Unfortunately, field club sport athletes do not have the opportunity to utilize functional screening tools. Further, normative data of Functional Movement Screen Composite Scores (FMS CS) has yet to be established in this population. Objective: The purpose of this study was to establish normative FMS CS among field club sport athletes, and determine if years of participation and current hours spent per week training have a significant effect on FMS CS. Foot type and orthotic use was also compared with FMS CS. Design: The study was a descriptive screening study. Setting: The assessments took place at a weight room and athletic training room at a DI Mid-Atlantic university. Patients and Other Participants: Thirty-one athletes (age 19.61 \pm 1.56 yrs, height $169.58 \pm 8.66 \mathrm{~cm}$, weight $72.77 \pm 17.42 \mathrm{~kg}$ ) participating in club soccer, rugby and lacrosse at a Division I Mid-Atlantic university during the 2017-2018 season volunteered for this study. Inclusion criteria for the study consisted of college students who are field club sport athletes between 18-23 years old who had not sustained an injury in the past twelve months that required removal from participation and training and completed the consent form. Exclusion criteria for the study consisted of an injury occurring in the past twelve months that required removal from participation and training and individuals not between the ages of 18-23 years old. Intervention: All participants completed the demographic questionnaire and seven movements of the FMS. A demographic questionnaire was completed to determine self-reported years of participation in the sport, number of hours spent training per week, foot type, and orthotic use. The participants were asked to complete the seven movements and three clearing tests of the FMS. Each participant completed three trials for each movement. Scores were calculated to determine FMS CS. Main Outcome Measures: The dependent variables were the Functional Movement Screen Composite Score and seven individual movement scores. Results: The mean FMS CS and standard deviation for all participants was 15.1 \pm 1.49 . Women's Lacrosse $(\mathrm{n}=4)$ had the highest average FMS CS (16.0 \pm 0.0$)$. Participants with fewer years in sports $(15.29 \pm 1.2$ vs14.94 \pm 1.71$)$ and hours of participation $(15.17 \pm 1.63$ vs $15 \pm 1.36)$ scored higher on the FMS CS. Those not wearing orthotics $(n=28,15.2 \pm 1.34)$ scored higher than those who do wear orthotics $(n=3,14.0 \pm 0.0)$. The one participant that reported a pes planus foot $(15.0 \pm 0.0)$ scored higher than the seven participants with a pes cavus foot (14.7 \pm 1.98$)$. Conclusions: Collegiate field club sport athletes score higher or comparable to varsity collegiate athletes on the FMS. More years of participation and hours per week were associated with decreased FMS. 
ACKNOWLEDGEMENTS

I would like to first start by thanking my parents. Everything about me is the amazing joint effort of two wonderful, loving parents. Having you as parents will never be taken for granted. I love you both.

Second, I want to thank my girlfriend Nicole. Our competitiveness has helped drive me to become a better person. Your love, along with an understanding of my pursuits, is something that I will always be thankful for. I love you hun.

My classmate Brian Hanson must be thanked, for he was my only classmate to join me on this endeavor. Your work ethic encouraged me to hold a higher standard for myself. I know you will do great things my friend.

My roommates DJ and Adam need to be thanked. They were a monumental part of my graduate experience. I know the three of us have created a friendship that will not fade with time.

To my supervisor, Dr. Vincent Stilger, thank you for providing the opportunity over the last two years for me to develop as an instructor and clinician. I am beyond fortunate to have worked with you.

Thank you to my committee members, Dr. Jean McCrory and Patti Riley. Your time and dedication are greatly appreciated.

Lastly, this opportunity would not be possible without my committee chair and Graduate Athletic Training Program Director, Dr. Michelle Sandrey. Thank you creating the opportunities and experiences for my classmates and I, and the copious hours spent diligently reading my drafts. I am thankful for the level of excellence you pushed me to reach. 


\section{TABLE OF CONTENTS}

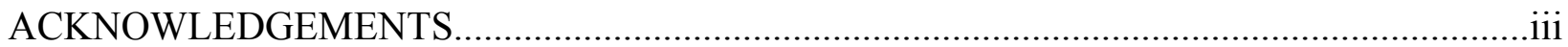

LIST OF TABLES

INTRODUCTION

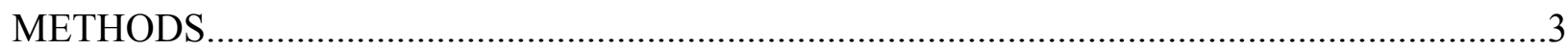

RESULTS

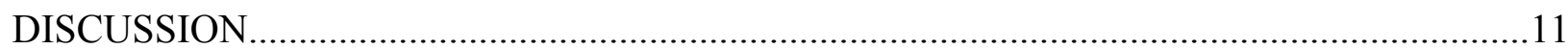

CONCLUSION

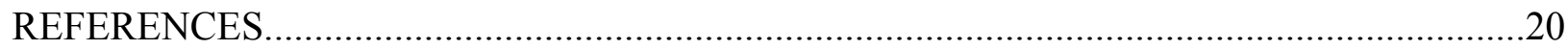

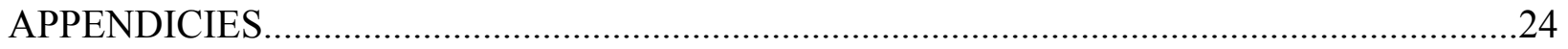

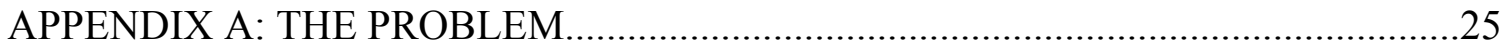

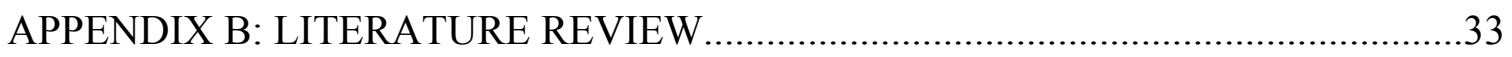

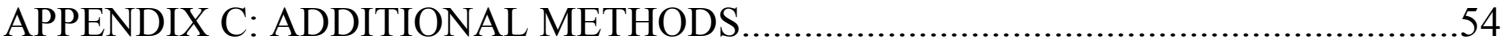

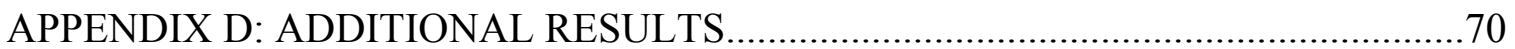

APPENDIX E: RECOMMENDATIONS FOR FUTURE RESEARCH..........................72

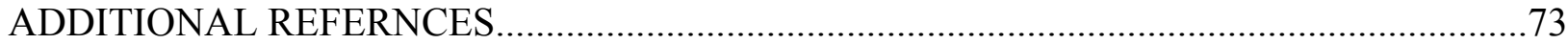




\section{LIST OF TABLES}

Table C1. Consent Information and HIPAA Form.....................................................................

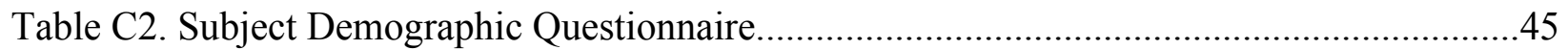

Table C3. Verbal Instructions for the Functional Movement Screen..............................................46

Table C4. Functional Movement Screen Score Procedures.............................................................50

Table C5. Functional Movement Screen Scoring Sheet...............................................................54

Table D1. Most Frequent, Frequency, and Mean For FMS CS and Individual Movements..........70

Table D2. Descriptive Statistics and ANOVA for Year in Sport...................................................70

Table D3. Descriptive Statistics and ANOVA for Hours per Week...............................................70

Table D4. Individual FMS Scores Related To Orthotics and Foot Type........................................71 


\section{INTRODUCTION}

The obesity epidemic has created awareness for the importance of an active lifestyle. Thus, athletic participation has been increasing at all competition levels. One place where this has become apparent is at the university setting. Universities and colleges offer numerous types of physical activity. College students, in general, have the opportunity to participate in recreational sports or club sports. An increase in participation at this level has unfortunately resulted in a rise of injury rates across club sports. Eight and eight tenths million recreationrelated injuries were reported between 2011-2014 in the United States. ${ }^{1}$ There were 1.4 million emergency department (ED) visits caused by recreational activity from $2000-2001{ }^{2}$ There are approximately $11,000 \mathrm{ED}$ visits each day in the U.S. related to recreational injury. ${ }^{2}$

Field club sports offered at colleges and universities include soccer, rugby, and lacrosse. Compared to varsity collegiate sports, field club sport athletes lack similar levels of commitment and access to sports medicine and strength and conditioning professionals. Six and three tenths injuries occurred per 1,000 athlete exposures among youth lacrosse players. ${ }^{3}$ Six hundred fifty nine injuries were experienced among 369 intercollegiate rugby players during a five year span. ${ }^{4}$ There were 12,974 injuries to collegiate male soccer players between 1988-2003. ${ }^{5}$

Despite decreased commitment and availability of resources, field club sport athletes are persistently seeking methods to improve performance and reduce risk of injury. Increasing speed, power, and strength are given priority over recovery and injury prevention measures. ${ }^{6}$ Increased training demands reinforce existing musculoskeletal asymmetries and limitation that lead to poor functional movement patterns. ${ }^{7-11}$ These compensation patterns build fitness upon dysfunction. ${ }^{7-}$

${ }^{11}$ Deficient movement patterns can lead to injury overtime. Clinicians rehabilitating injuries cannot disregard functional movement patterns to prepare an athlete for return to play. One such 
screening tool that can be used is the Functional Movement Screen (FMS). The FMS was originally developed to serve as an inexpensive, simple screening tool for functional movement quality. ${ }^{12}$ The seven movements were selected to recreate the demands of athletic performance and activities of daily living. ${ }^{12}$ Screening tools, like the FMS, are designed to assess musculoskeletal asymmetries and limitations displayed during functional movement patterns. ${ }^{7-11 \text {, }}$ 13, 14

High injury rates and deficient movement patterns have encouraged athletic trainers and strength and conditioning coaches to implement movement screenings. High school athletes, varsity collegiate athletes and professional athletes participating in the field sports of rugby and soccer have received significant attention for musculoskeletal assessments using FMS composite scores (CS). ${ }^{15-20}$ Twenty-two male recreational team sport athletes participating in soccer, basketball, rugby league, rugby union, Australian football, or touch football were assessed. ${ }^{15,16}$ The mean FMS CS equated to $15.09+2.18 .{ }^{15,16}$ In contrast, 62 South African professional rugby union players completed the FMS to compare CS between injured and non-injured athletes. ${ }^{17}$ The FMS CS was $13.2 \pm 1.7$ vs. $14.5 \pm 1.5$, which is lower than in the Lockie ${ }^{15,16}$ study. Seventysix male union rugby players completed the FMS at the beginning of each half of a season. An insignificant difference in FMS CS was noted between the first and second half of the season, 15.2 \pm 1.94 vs. $15.4 \pm 2.05 .{ }^{18}$ Twenty-three U16 and twenty-five U19 youth elite soccer players completed the $\mathrm{FMS}^{21}{ }^{11}$ Functional movement scores were $13.87+2.93$ vs. $14.96+2.07 . .^{21}$

Negligible differences were noted within individual FMS movements between the two age groups. ${ }^{21}$ A comparison between NCAA Division II men's and women's soccer players was conducted to assess differences in FMS CS. ${ }^{19}$ Men's soccer scored slightly higher than women's soccer, $16.16 \pm 1.54$ vs. $15.78 \pm 1.85 .{ }^{19}$ Forty-seven Division II men's and women's soccer players 
averaged a 15.84+1.73 FMS CS. ${ }^{20}$ Sixty-two Division I women’s soccer players had an average FMS CS of $14 .^{22}$

The collegiate field club sport athlete population has not been thoroughly examined throughout the literature. There is no specific screening tool for the club sport athlete, but the FMS could serve the needs of this population. The FMS is a simple, quick movement screening tool to develop an individualized functional movement profile. There is little evidence of screening tools that have examined field club sport athletes in the literature. Application of the FMS and its utility with this population needs further investigation. There are a lack of normative data examining how collegiate field club sports score on the FMS. The rise of athletic participation and subsequent injuries must be matched with injury prevention programs. The movement deficiencies discovered during the FMS can be used to develop an individualized intervention to correct musculoskeletal asymmetries and limitations.

As the number of field club sport athletes grows, the need to detect movement deficiencies increases. Implementation of a functional movement screening tool is required to detect these deficiencies. Therefore, the purpose of this study is to establish normative FMS CS among field club sport athletes, and determine if years of participation and current hours spent per week training have a significant effect on FMS CS.

\section{METHODS}

This study was descriptive screening study to determine Functional Movement Screen Composite Scores (FMS CS) across field club sport athletes at a Mid-Atlantic university. Participants were tested during one session. The participants were in-season and out of season. The FMS was used to detect compensation patterns and movement deficits in field club sport athletes. The dependent variable was the FMS CS of each sport (Lacrosse, Soccer, Rugby). 
Independent variables were the self-reported number of years playing $(>10,<10)$ and selfreported number of training hours per week $(>12,<12)$.

Participants

A total of 31 student-athletes participating in field club sports at a Mid-Atlantic university were recruited during the 2018 club sport season or off season. A demographic questionnaire was provided to each participant. This included demographic information, training hours per week, years of participation, and injury history to determine eligibility for the study. A club sport athlete was defined as an individual who voluntarily participates in sports without the benefit of a scholarship or other benefits provided to a varsity sport athlete. Inclusion criteria for the study included college students 18-23 years old who had not sustained an injury in the past twelve months that required removal from participation and training and completed the consent form. Exclusion criteria included an injury in the past twelve months that required removal from participation and training and will be not between the ages of 18-23 years old. Participants completed all seven movements of the FMS in order for the results to be used in this study. The Office of Research Compliance at the institution approved the study.

Procedures

Athletes who were currently participating in field club sports (Lacrosse, Rugby and Soccer) were approached by the primary researcher to become participants in the study. The potential participants were explained the purpose of the study. An informed consent (Table C1) was provided to each consenting participant before the start of the study. A demographic questionnaire (Table C2) was provided to each participant. Those participants who met the inclusion criteria were invited to participate in this study. Times were scheduled for the participants to meet with the primary researcher to complete the FMS. Attendance at one 20 
minute screening was required for each participant. Participants were permitted to engage in normal practices, competitions, and training sessions. Clothes, socks, and shoes were selected by the participants. The FMS was performed in the athletic training room and research laboratory at a Mid-Atlantic university to control for external factors. Administration and supervision of all screenings was conducted by the primary researcher.

Verbal Instructions for the FMS (Table C3) were administered as the participants performed the seven functional movements and three clearing tests. Standard FMS Scoring Procedures (Table C4) were used. Movements scores were scored from zero to three. Clearing tests were completed prior to three movements: shoulder mobility, trunk stability push-up, and rotary stability. If pain was elicited, a score of zero is given. If there was an absence of pain, the participant was permitted to perform the movement. A score of three represented completion of the movement without compensation, two demonstrated completion of the movement with compensation, and one identified movements that were not completed. The raw score was used to identify right and left side scoring. The final movement score demonstrated an overall score. The sum of all seven movements determined the FMS CS.

Previously described testing procedures were developed by Cook. ${ }^{7-11}$ Each movement was limited to three trials. A warm-up protocol was not included. A script was read (Table C3) to ensure consistency and clarity of instructions for each movement. No cueing was provided during the movements. The raw score was used to differentiate between right and left side scoring. The final score was used to display the overall score of the test. The lowest score for the raw score on each side was carried over to give a final score for the test.

Reliability of the FMS has been found to be as high as $.98 .^{7-11}$ Other studies have discovered the reliability of the FMS to range from moderately high to high $(\mathrm{r}=0.87-0.89,0.971$, 
0.92-0.98) ${ }^{7-11}$ Level of experience with the FMS has a direct relationship to reliability. ${ }^{12}$ Recent research has focused on assessing the validity of the FMS on the screening tool's ability to assess injury risk and athletic performance. Numerous studies ${ }^{13,17}$ compare mean FMS CS between injured versus non-injured groups. These studies collectively agree that the differences in FMS CS are insignificant. In the current literature, higher FMS CS do not mean greater athletic performance measures such as multidirectional speed, jumping, $\mathrm{Y}$ balance test, 1RM squat, ten and twenty meter sprints, and T -test times. ${ }^{15,}{ }^{16}$ Most validity studies on the FMS do not focus on the ability to assess musculoskeletal asymmetries and limitations.

The FMS (Tables C3-5) was designed to assess fundamental movements of an individual. ${ }^{7-11}$ The goal was to identify musculoskeletal asymmetries and limitations. These findings determined the design of an individualized intervention. The seven movements of the FMS include the: deep squat, hurdle step, in-line lunge, shoulder mobility, active straight leg raise, trunk stability push-up, and rotary stability.

The deep squat (Table C3) was used to assess bilateral, symmetrical, functional mobility of the hips, knees and ankle. ${ }^{7-11}$ A dowel was grasped and placed horizontally overhead so the shoulders and elbows are at ninety degrees. The dowel was extended overhead to assess thoracic and shoulder mobility. An upright torso and heel contact was maintained as the participant descends as deep as possible. ${ }^{7-11}$ The participant held the descend position for a count of one, and then returned to the starting position. ${ }^{7-11}$ The participant had a maximum of three trials to complete the movement to the best of their ability.

The hurdle step (Table C) emphasizes proper stride mechanics. The hurdle height was equivalent to the participant's tibial tuberosity. ${ }^{7-11}$ The participant placed toes on the test and placed the dowel across the back of the shoulders. At this point, the participant raised one leg to 
step over the hurdle to contact the heel with the ground. ${ }^{7-11}$ This movement was assessed bilaterally. The participant had a maximum of three trials to complete the movement to the best of their ability.

The inline lunge (Table C3) imposed a narrow base of support to challenge the stability of the trunk and extremities. ${ }^{7-11}$ The participant grasped a dowel behind the back before stepping onto the $2 \times 6$ board. Tibial tuberosity height was measured to determine the distance between the feet. ${ }^{7-11}$ The left leg stepped forward as the right hand grasped the dowel behind the neck. The participant descended until the right knee touched the $2 \times 6$ board and returned to the starting position. ${ }^{7-11}$ The movement was assessed bilaterally. The participant had a maximum of three trials to complete the movement to the best of their ability.

The shoulder mobility (Table C) movement assessed bilateral mobility of the shoulder, scapula, and thoracic spine. ${ }^{7-11}$ The participant made fists with the thumb inside. The right fist reached overhead and down the spine. The left fist went behind and up the spine as far as possible. Creeping, or connecting movements, of the fists was prohibited. ${ }^{7-11}$ The distance between the two fists was measured in inches. This score was assigned to the flexed shoulder. The movement was assessed bilaterally. The participant had a maximum of three trials to complete the movement to the best of their ability.

The shoulder clearing test (Table C) was performed after the shoulder mobility movement. No score was assigned to this movement. The purpose of this test was to assess for pain. The right palm was placed on top of the left shoulder. While maintaining contact, the right elbow was raised as high as possible to determine if shoulder impingement is present. ${ }^{7-11}$ If pain was present, a score of zero was given. ${ }^{7-11}$ The clearing test was performed bilaterally. 
The active straight leg raise (Table C) assessed the flexibility of the hamstrings and gastroc-soleus complex as the pelvic and core maintained stability. ${ }^{7-11}$ The participant remained flat with the back of the knees against the $2 \times 6$ with the toes pointed upward. The stationary left leg maintained contact with the floor and a dorsiflexed ankle. ${ }^{7-11}$ A midpoint was identified between the anterior superior iliac spine and middle of the patella. A dowel was placed perpendicular to the floor at the midpoint. The right foot was kept straight and raised as high as possible with the head and lower back in contact with the floor. If the malleolus did not pass the dowel, the dowel was moved in line with the malleolus of the test leg and scored per the criteria. ${ }^{7-11}$ The movement was assessed bilaterally. The participant had a maximum of three trials to complete the movement to the best of their ability.

The trunk stability push-up (Table C) assessed stabilization of the core and spine through a closed-chain upper body movement. The participant laid face down with the feet together, and the hands spaced shoulder-width apart. ${ }^{7-11}$ The thumbs were placed in line with the chin. The participant raised the body as a unit with knees extended and ankles dorsiflexed to complete one push-up. If one push-up was performed, the hands were lowered to shoulder level. ${ }^{7-11}$ The participant had a maximum of three trials to complete the movement to the best of their ability.

The spinal extension clearing test (Table C) was performed after the trunk stability pushup. No score was assigned to this movement. The purpose of this test was to assess for pain. The participant was prone with the palms under the shoulders. With no movement from the lower body, the participant pressed up. If pain was present, a score of zero was given. ${ }^{7-11}$

The rotary stability movement (Table C) required proper neuromuscular coordination and energy transfer from one segment of the body to another through the torso. ${ }^{7-11}$ The participant was placed in a quadruped position with the hips and shoulders at 90 degrees relative to the 
torso. ${ }^{7-11}$ The $2 \times 6$ board was placed between and made contact with the hands and knees. ${ }^{7-11}$ The arm and leg on the same side were lifted to attempt to touch the knee and elbow. ${ }^{7-11}$ If this movement was performed, the participant was instructed to perform a diagonal pattern. The movement was assessed bilaterally. The participant had a maximum of three trials to complete the movement to the best of their ability.

The spinal flexion clearing exam (Table C) was performed after the rotary stability movement. No score was assigned to this movement. The purpose of this test was to assess for pain. The participant started in a quadruped position and rocked backwards to touch the buttocks to the heels and chest to the thighs. ${ }^{7-11}$ The shoulders remained flexed with the hands reaching as far as possible. ${ }^{7-11}$ A score of 0 was given if pain was noted.

Data Analysis

The FMS scores were recorded (Table C5). The final score included the lowest score of the movement with right and left values. The highest possible FMS CS was 21. The values gathered were assessed within each sport and across normative values of other sports. Statistical Analyses

Descriptive analyses included means and standard deviations for all participants with the FMS, including FMS CS across sports. The overall mean FMS CS for lacrosse, soccer, and rugby will be compared to hours spent training per week, number of years participating in the sport, foot type, and orthotic use. Four separate one-way ANOVA's were calculated to compare mean FMS CS with 1) hours spent training, competing, practicing and training per week $(\geq 12$ hours and $<12$ hours); 2) the number of years participating in the sport ( $\geq 10$ and $<10$ years); 3 ) foot type (pes planus and pes cavus); and 4) orthotic use ( yes and no). ANOVA's will be calculated with $95 \%$ Confidence Intervals. The $\mathrm{P}$ value will be set to $\mathrm{P}=0.05$ for all analyses. 
IBM/SPSS software (IBM/SPSS, Inc., Chicago, IL) version 24.0 was used for all analyses. It is beneficial to understand how club field sport athletes scores compared to other athletic populations.

RESULTS

Demographic Data

Thirty-one athletes (age 19.61 \pm 1.56 yrs, height $169.58 \pm 8.66 \mathrm{~cm}$, weight $72.77 \pm 17.42 \mathrm{~kg}$ ) participating in club soccer, rugby and lacrosse at a Division I Mid-Atlantic university during the 2017-2018 season volunteered for this study. Beyond the 31 participants, one athlete was excluded due to a recent injury. Fourteen (45.2\%) of the participants were from women's soccer, $1(3.2 \%)$ from men's soccer, $4(12.9 \%)$ from women's rugby, $8(25.8 \%)$ from men's rugby, and $4(12.9 \%)$ from women's lacrosse. Thirteen (41.9\%) participants were freshman, $9(29.0 \%)$ were sophomores, 4 (12.9\%) were juniors, and 5 (16.1\%) were seniors. All participants were free of injury for the past six months that prevented full participation in their sport.

FMS Composite and Individual Scores for Years of Participation and Contact Hours

Table D1 displays the overall FMS CS, FMS CS for individual sports, average for individual movement scores and individual movement scores for each sport. The mean FMS CS for all participants $(n=31)$ in the study was $15.1 \pm 1.49$ (minimum score of 11 , maximum score of 18). Women's Lacrosse had the highest average FMS CS (16.0 $\pm 0.0, n=4)$. Average individual FMS scores were reported for DS (1.971 \pm 0.31$)$, HS (2.091 \pm 0.40$),$ IL (2.481 \pm 0.57$),$ SM (1.91 \pm 0.83$), \operatorname{ASLR}(2.651 \pm 0.55)$, TSPU (2.031 \pm 0.66$)$, and RS (2.0 \pm 0.0$)$. For average individual movement scores, women's and men's soccer had the highest average individual movement score in the IL $(2.57 \pm 0.51,3.0 \pm 0.0)$. Women's and men's rugby, and women's lacrosse scored best in the ASLR $(3.0 \pm 0.0,2.63 \pm 0.52,3.0 \pm 0.0)$. 
Table D2 compares years in sport with FMS CS and individual movement scores. There were no significant differences between FMS CS and years of participation in their sport $(\geq 10$ years, $<10$ years $)(\mathrm{F}=0.402, \mathrm{P}=0.531)$. Individually, years of participation was significant for TSPU $(\mathrm{F}=4.199, \mathrm{p}=0.050)$. Table D3 presents descriptive statistics and results for contact hours. No significant differences were found between FMS CS and hours per week spent training, practicing, and competing ( $\geq 12$ hours, $<12$ hours $)(\mathrm{F}=0.104, \mathrm{P}=0.104)$. Individual movement scores were not significant. The movement closest to significance when compared to hours per week was the DS $(\mathrm{F}=2.967, \mathrm{p}=0.096)$.

FMS Composite and Individual Scores in Relation to Foot Type and Orthotics

The DS, HS, and IL were the only scores compared to foot type and orthotics. A pes

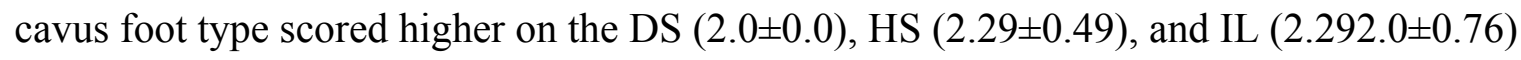
compared to pes planus. The one participant with pes planus had a higher FMS CS $(15.0 \pm 0.0)$ than the 7 participants with pes cavus $(14.7 \pm 1.98)$. This same participant with pes planus did not wear orthotics. Participants that do not wear orthotics scored highest on the IL (2.54 \pm 0.51$)$. Three participants wore orthotics, and averaged 2.0 \pm 0.0 for the DS, HS, and IL. Participants not wearing orthotics had a higher average FMS CS (15.2 \pm 1.34$)$ than those who wear orthotics $(14.0 \pm 0.0)$

\section{DISCUSSION}

This study was conducted using field club sport athletes to establish normative FMS CS and determine the impact of years of participation and hours spent practicing, training, and competing. Foot structure and orthotic use was evaluated to determine the effect on FMS CS and

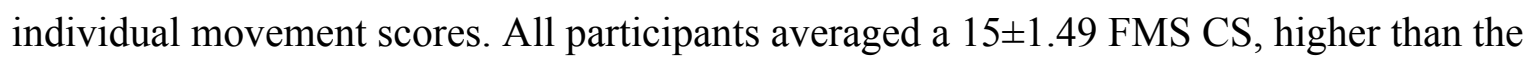
hypothesized 14 . The hurdle step and rotary stability were expected to be the highest and lowest 
individual movement scores. In this study, the ASLR was the highest (2.65 \pm 0.55$)$ and SM was the lowest $(1.91 \pm 0.83)$ individual movement scores. Unfortunately, 31 participants do not offer enough scores to establish normative values. Plus, the majority of participants were female and women's soccer players. There was one men's soccer, four women's lacrosse, and zero men's lacrosse players. This concept of establishing normative data must be continued for these sports to effectively correct movement deficiencies.

The hypotheses that those who participated $\geq 10$ years in sport $(14.94 \pm 1.71)$ and $\geq 12$ hours per week (15 \pm 1.36$)$ would have an FMS CS score lower than those $<10$ years $(15.29 \pm 1.2)$ and $<12$ hours $(15.17 \pm 1.63)$ was exhibited in this study. Participants without orthotics $(15.2 \pm 1.34)$ scored higher on the FMS CS than those who do wear orthotics (14.0 \pm 0.0$)$. The participant with

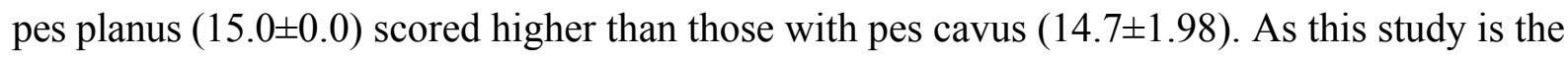
first study to evaluate club sport field athletes with the FMS, it is difficult to draw direct conclusions with comparisons to other known studies in this area. However, comparisons can be made using the FMS literature in other sports and populations.

FMS CS and Individual Scores

Athletes are continuously training harder to perform better in their sport with the "more is better" mentality. Despite an athlete's effort and discipline in their training regiment, movement insufficiencies may be present. The FMS is designed to assess musculoskeletal asymmetries and limitations. Based on the results, an individualized intervention is developed to correct movement deficiencies. With the information obtained from the FMS, an athlete's inefficient movement patterns can be corrected prior to the start of a season or training cycle. In this study, all participants averaged a $15 \pm 1.49$ on the FMS CS. Despite being a club sport athlete, the 
participants in this study scored better or similarly to athletes participating in the same sport at different competition levels.

U16 and U19 youth elite soccer players averaged $13.87 \pm 2.93$ and $14.96 \pm 2.07 .{ }^{21}$ These younger athletes scored lower than female and male club soccer athletes $(14.9 \pm 1.44,15.0 \pm 0.0)$. Silva ${ }^{24}$ stated the difference between U16 and U19 FMS CS could be a result of the ability to control multi-planar trunk stability. The mature club sport athletes may have developed better multi-planar stability and strength, leading to higher FMS CS. Forty-seven NCAA Division II men's and women's soccer players between the ages of 17-22 scored significantly higher than the soccer players in this study $(16.16 \pm 1.54,15.78 \pm 1.85) .{ }^{20}$ Another study examining FMS CS on 47 Division II men's and women's soccer players found an average of $15.84 \pm 1.73 .{ }^{19}$ These findings suggest that soccer players at higher levels of competition score higher on the FMS CS. Although, differences in FMS CS could be consequence of when screenings are performed. Screening in this study was conducted in the off-season, and the previously mentioned studies were performed during the pre-season.

Rugby and lacrosse players scored higher or comparable to the results from this study. Seventy-six male union rugby players scored comparable FMS CS $(15.2 \pm 1.94)$ to those male and female club rugby players $(15.3 \pm 2.05,14.5 \pm 1.29) .{ }^{18}$ Only injury-free athletes were eligible to participate in these studies. Sixty-two non-injured South African professional rugby union players scored 14.5 \pm 1.5. Unlike soccer, competition level has is an insignificant effect on FMS CS. The women's lacrosse athletes had the highest average FMS CS of 16.0土0.0. Lacrosse players may have improved coordination between the trunk with upper and lower extremities. Their sport demands wielding a lacrosse stick to throw, as soccer and rugby do not involve equipment that act as extensions of their extremity. 
Twenty-two of 31 participants were females in this study. Females are generally more flexible than males. A study of 492 male and 118 female high school athletes were examined to determine sex differences in hamstring flexibility. ${ }^{24}$ Females displayed greater hamstring flexibility. ${ }^{24}$ On the contrary, males reported hamstring flexibility to be more important for athletic performance and to their coaches. ${ }^{24}$ Both sexes reported similar stretching duration and repetitions. ${ }^{24}$ Despite a lack of perceived importance, female athletes displayed greater hamstring flexibility. ${ }^{24}$ Overall, it is difficult to discern if hours per week or sex differences are the cause in FMS CS and individual movement scores.

In this study, when individual scores were evaluated, SM had the lowest average score when compared with hours per week. The TSPU and SM concentrate on the upper extremity. Female athletes have typically demonstrated decrease performance in upper extremity strength, endurance, and neuromuscular control. ${ }^{23}$ Another study compared 29 female and 31 male secondary school athletes and found females scored significantly lower on the TSPU (1.4 \pm 0.6 vs. $2.2 \pm 0.8) .{ }^{23}$ Ninety-three percent of females and $65 \%$ of males required modification or were unable to complete the push-up with modification. An additional study ${ }^{23}$ also found Division I females to score lower on the TSPU and RS when compared to males, but better on the SM. As previously discussed, females tend to have better flexibility, explaining why other studies display improved performance on SM. Poor performance on the TSPU may also be related core strength and stabilization.

FMS CS and Individual Scores and Years of Participation and Contact Hours Participants with $<10$ years in sport $(\mathrm{n}=14)$ and $<12$ hours per week $(\mathrm{n}=17)$ scored higher. The highest individual movement score was the ASLR. Participants with $<10$ years in sport $(\mathrm{n}=14)$ and $<12$ hours per week $(\mathrm{n}=17)$ scored higher. Studies related to FMS CS to years 
participating in sport are scarce in the literature. However, a study by Bardenett ${ }^{25}$ found high school athletes with more years of experience to score lower on the FMS $(13.11 \pm 1.69$ vs $13.00 \pm 2.32)$. The largest difference in individual movement scores was with the SM $(2.67 \pm 0.55$ vs $2.23 \pm 0.84) .{ }^{25}$ The study concluded that lower scores were attributed to previous injury history and increased exposure time in high level varsity athletics. ${ }^{25}$ Another study found $60 \%$ of junior Australian Football players to score lower than older, professional American Football players and collegiate athletes. ${ }^{26}$ Despite conflicting evidence, this study found athletes with more years of participation in their sport had decreased FMS CS and individual movement scores. In this study, the TSPU displayed the lowest individual mean score when compared with years in sport. Aging may also be a consideration as older individuals are usually playing for a longer period of time. The effects of aging negatively impact performance on the FMS. ${ }^{27,28}$ A study of 395 men and 227 women were screened and divided into six different age groups. ${ }^{27}$ Males and females between 20-29 years of age had higher FMS CS than the 65+ years group (14.79 \pm 2.76 , $15.43 \pm 2.44$ vs. $12.56 \pm 3.27,13.17 \pm 3.01) .{ }^{27}$ Another study found men and women $65+$ years to score lower on the FMS $(12.6 \pm 3.3,13.2 \pm 3.0){ }^{28}$

The amount of time spent per week training, practicing, and competing is thought to negatively affect FMS CS. A study of 84 collegiate middle and long distance runners compared FMS CS, injury, and weekly mileage. ${ }^{29}$ Injury-free runners ran fewer miles $(80.9 \pm 53.8$ vs 98.4 \pm 57.3 ), but scored higher than the injured runners (14.4 \pm 2.2 vs $13.3 \pm 2.7) .{ }^{29}$ Another study classified runners as functional ( $\geq 14$ FMS CS) or dysfunctional $\left(<14\right.$ FMS CS).${ }^{30}$ Similar to the study by Hotta, ${ }^{29}$ dysfunctional runners displayed an increase in training sessions per week and injury prevalence in the past 12 months. ${ }^{30}$ Increases in mileage provide more opportunity to develop movement deficiencies and musculoskeletal asymmetries and limitations, leading to 
lower FMS CS. One study reported 13.8 injuries occur per 1,000 athlete exposures among collegiate athletes. ${ }^{31}$ More deficiencies may present among injured athletes. ${ }^{31}$ The FMS could be compared with athlete-exposures to determine if contact-hours affect FMS CS.

Foot Type and Orthotics

As foot type and orthotics have an influence on movement patterns, it was hypothesized that similar differences would be apparent in this study. Differences were noted in this study between participants with a pes planus or pes cavus foot type. The one participant with pes planus scored higher than the 7 participants with pes cavus $(15.0 \pm 0.0$ vs. $14.7 \pm 1.98)$. The comparison is intriguing but a lack of participants does not make the finding significant. With only one participant having a pes planus foot, that difference was not as apparent. Participants not wearing orthotics scored higher than those wearing orthotics (15.2 \pm 1.34 vs. 14.0 \pm 0.0$)$. Those without orthotics scored highest in the IL $(2.54 \pm 0.51)$. It could be thought that these individuals have stronger intrinsic foot musculature that prevent pronation distortion syndrome of the lower extremity. $^{29}$

Since foot type and orthotic use was evaluated in this study, there may be concern that the FMS instructions do not provide guidelines on whether participants should wear shoes or be barefoot during screening. The argument for FMS when barefoot is to improve stability through increased sensory input through the feet. Plus, barefoot screening will also be a more accurate representation on how foot type can impact FMS CS and individual movement scores. ${ }^{32}$ On the contrary, a lack of support to screen participants with shoes also lessens the importance to screen those wearing orthotics. ${ }^{32}$ Participants were divided into shoe and barefoot groups in the Crosby study $^{32}$ to compare the DS, HS, IL, and FMS CS. There were no significant differences and it was inferred that footwear does not provide supplementary stability. ${ }^{32}$ Despite the increased 
sensory input of barefoot screening, athletes and all other participants wear shoes during almost every moment of the day. ${ }^{32}$ Thus, barefoot screening does not accurately recreate functional movement patterns as they are performed in the real world. It is also important to note that the DS is intended to be a measure of mobility, not stability.

\section{Clinical Implications}

The results from this study provided introductory descriptive data of FMS CS and individual movement scores for collegiate club sport athletes. As this population is underrepresented in the literature, more information is needed to determine where deficiencies are most likely to exist so interventions can be initiated earlier. Despite lacking the benefits afforded to varsity collegiate athletes such as the same time commitments, resources, coaching and tools to improve functional movement, club sport athletes scored similarly or better. The mean FMS CS for all participants in the study was $15.1 \pm 1.49$. This is very comparable to the eighty-four Division II rowers, volleyball, and soccer players that averaged an FMS CS of $15.84 \pm 1.73,{ }^{20}$ as well as 108 Division I collegiate athletes with a FMS CS of $15.5^{46}$. However, a lower mean FMS CS of $14.3 \pm 2.2$ was found after examining 59 Division I freshman football players. With similar or better results for FMS CS in comparison to collegiate athletes at different competition levels, the availability of resources and coaching do not appear to have a significant effect on FMS CS.

On average, the DS and SM were the lowest scored movements. Both movements emphasize mobility, indicating field club sport athletes are deficient in ankle, hip, spine, and shoulder mobility. Most athletes do not emphasize stretching and mobility in the training regiments. Interventions techniques including static stretching, self-myofascial release, foam rolling, instrument-assisted soft tissue mobilization, joint mobilizations and dynamic stretching 
can be incorporated to improve individual deficiencies. The negative effects of increased years of participations and hours per week can be counteracted by an individualized intervention developed on FMS scores. Years of participation and hours per week did not significantly affect FMS CS. Clinicians can use this information to develop more effective interventions. This should raise awareness that more research is needed to determine other factors that impact FMS CS. At this time, clinicians should not be concerned about the impact of years of participation and hours spent per week have on functional movement patterns. Although information from this study pertaining to orthotics and foot type in limited, no orthotics and pes cavus may require a more detailed biomechanical analysis of the lower extremity. These groups scored lower in FMS CS, DS, IL, and HS, suggesting abnormalities in the foot are causing stability or mobility deficiencies in proximal joints. Overall, the emphasis is to reestablish functional movement patterns and educate athletes to train smarter, striving to increase the number of years of participation.

Limitations of the Study

The data from this study are preliminary and further investigation is necessary to establish normative data for this population. Thirty-one participants do not offer enough data since it is estimated that there are approximately 700 athletes at this Division I Mid-Atlantic university. A lack of participants makes it difficult for this data to be generalizable to all field club sport athletes. The study also had a greater representation of female field club sport athletes, decreasing its generalizability to male athletes. Also, the participant's foot type and orthotic use was determined through self-report on a questionnaire, rather than implementing an objective measurement. This study displayed that most participants do not know their foot type, limiting the amount of data collected. Future studies should include specific measurements of foot type. 


\section{CONCLUSION}

Functional Movement Screen studies using field club sport athletes should be conducted. Results from this study indicateD that the FMS CS was higher or comparable to other varsity collegiate athletes. In addition, women's lacrosse players had the highest mean FMS CS. Participants who reported greater years of participation and hours spent per week had a negative association with FMS CS. Not wearing orthotics and pes planus displayed higher FMS CS. The information gained from this and future studies using field club sports athletes will help in the understanding of movement deficiencies and musculoskeletal asymmetries and limitations specifically present in this population. 


\section{REFERENCES}

1. Sheu Y, Chen L, Hedegaard H. Sport and recreation related injury episodes in the u.s. population: 2011-2014. Med Sci Sport Exerc. 2016;48:868.

2. National Center for Injury Prevention and Control (U.S.). CDC injury research agenda, 20092018. Atlanta, GA: US Department of Health and Human Services, Centers for Disease Control and Prevention; 2009. Available at: http://www.cdc.gov/ncipcl

3. Lincoln AE, Yeger-McKeever M, Romani $\mathrm{W}$ et al. Rate of injury among youth lacrosse players. Clin J Sport Med. 2014;24(4):355-357.

4. Peck KY, Johnston DA, Owens BD et al. The incidence of injury among male and female intercollegiate rugby players. Sports Health. 2013;5(4):327-333.

5. Agel J, Evan TA, Dick R, Putukian M, Marshall SW. Descriptive epidemiology of collegiate men's soccer injuries: national collegiate athletic association injury surveillance system, 1988-1989 through 2002-2003. J Athl Train. 2007;42(2):270-277.

6. Mattila VM, Parkkari J, Koivusilta L, Kannus P, Rimpela A. Participation in sports clubs is a strong predictor of injury hospitalization: a prospective cohort study. Scand J Med Sci Sports. 2009;19:267-273.

7. Cook G, Burton L, Hoogenboom B J, et al. Functional movement screening: the use of fundamental movements as an assessment of function - part 1. Int J SportsPhys Ther. 2014;9(3):396-409.

8. Cook G, Burton L, Hoogenboom BJ, et al. Functional movement screening: the use of fundamental movements as an assessment of function - part 2. Int J SportsPhys Ther. 2014;9(4):549-563.

9. Cook G, Burton L, Hoogenboom B. Pre-participation screening: the use of fundamental movements as an assessment of function - part 1. N Am J Sports Phys Ther. 2006;1(2):6272.

10. Cook G, Burton L, Hoogenboom B. Pre-participation screening: the use of fundamental movements as an assessment of function - part 2. N Am J Sports Phys Ther. 2006;1(3):132139.

11. Cook G. Movement: Functional Movement Systems, Screening - Assessment - Corrective Strategies. Lotus Publishing; 2011.

12. Kraus K, Schutz E, Taylor WR, et al. Efficacy of the functional movement screen: a review. J Strength Cond Res. 2014;28(12):3571-3584. 
13. Clay H, Mansell J, Tierney R. Association between rowing injuries and the functional movement screen in female collegiate division I rowers. Int J Sports Phys The. 2016;11(3):345-349.

14. Everard E, Harrison A, Lyons M. To examine the relationship between the functional movement screen and the landing error scoring system in an active collegiate population. $J$ Strength Cond Res. 2016.

15. Lockie RG, Schultz AB, Callaghan SJ et al. A preliminary investigation into the relationship between functional movement screen scores and athletic physical performance in female team sport athletes. Biol Sport. 2014;32(41):41-51.

16. Lockie RG, Callaghan SJ, Jordan CA et al. Certain actions from the functional movement screen do not provide an indication of dynamic stability. J Hum Kinet. 2015;14(47):19-29.

17. Tee JC, Klingbiel FG, Collins R et al. Preseason functional movement screen component tests predict severe contact injuries in professional rugby union players. $J$ Strength Cond Res. 2016;30:11.

18. Duke SR, Martin SE, Gaul CA. Preseason functional movement screen predicts risk of timeloss injury in experienced male rugby union athletes. J Strength Cond Res. 2017;31(10)

19. Sprague PA, Mokha MG, Gatens DR. Changes in functional movement screen scores over a season in collegiate soccer and volleyball athletes. J Strength Cond Res. 2014;28(11).

20. Mokha M, Sprague PA, Gatens DR. Predicting musculoskeletal injury in national collegiate athletic association division II athletes from asymmetries and individual-test versus composite functional movement screen scores. J Athl Train. 2016;51(4):276-282

21. Silva B, Clemente FM, Camoes M et al. Functional movement screen scores and physical performance among youth elite soccer players. Sports. 2017;5(16)

22. Clifton DR, Grooms DR, Onate JA. Overhead deep squat performance predicts functional movement screen score. Int J Sports Phys There. 2015;10(5):622-627.

23. Anderson BE, Neumann ML, Huxell Bliven KC. Functional movement screen differences between male and female secondary school athletes. J Strength Cond Res, 2015;29(4):10981106.

24. Nyland J, Kocabey Y, Caborn DN. Sex differences in perceived importance of hamstring stretching among high school athletes. Percept Mot Skills. 2004;99(1):3-11.

25. Bardenett SM, Miccaa JJ, DeNoyelles JT, Miller SD, Jenk DT, Brooks GS, Functional movement screen normative values and validity in high school athletes: can the fms be used as a predictor of injury? Int J Sports Phys Ther. 2015;10(3):303-308. 
26. Fuller JT, Chalmers S, Debenedictis TA et al. High prevalence of dysfunctional, asymmetrical, and painful movement in lit junior Australian football players assessed using the functional movement screen. J Sci Med Sport. 2017;20(2):134-138.

27. Perry FT, Koehle MS. Normative data for the functional movement screen in middle-aged adults. J Strength Cond Res. 2013;27(2):458-462.

28. Fawcett, MA. Reliability of the functional movement screen score for older adults. Bowling Green State University. ProQuest Theses and Dissertations. 2014.

29. Hotta $\mathrm{T}$, Nishiguchi $\mathrm{S}$, Fukutani $\mathrm{N}$ et al. Functional movement screen for predicting running injuries in 18- to 24-year-old competitive male runners. J Strength Cond Res. 2015;29(10):2808-2815.

30. de Oliveira RR, Chaves SF, Lima YL et al. There are no biomechanical differences between runners classified by the functional movement screen. Int J Sports Phys Ther. 2017;12(4):625-633.

31. Dorrell BS, Long T, Shaffer S et al. Evaluation of the functional movement screen as an injury prediction tool among active adult populations: a systematic review and meta-analysis. Sports Heath. 2015;7(6):532-537.

32. Crosby BR. Analysis of barefoot and preferred footwear in functional movement screen scores. Illinois State University. ProQuest Theses and Dissertations. 2016. 
APPENDICIES 


\section{APPENDIX A}

\section{THE PROBLEM}

\section{Research Question}

Athletic participation has been growing rapidly. There are several levels of competition in which athletes can participate. At colleges and universities, students have the opportunity to be a club sport athlete. A surge in club sport participation has lead to an increase in injuries. ${ }^{43}$ Recreation related injuries were reported to be 8.8 million between 2011-2014 among the United States (U.S.) population. ${ }^{1}$ Exercising was the most frequently reported cause of injury. These injuries included 4.3 million strains and sprains, 2.1 million fractures, 2.0 million contusions, and 1.0 million open wounds. ${ }^{1}$ The Center for Disease Control (CDC) reported 1.4 million emergency department (ED) visits from 2000-2001 caused by recreational activity. ${ }^{2}$ Approximately 11,000 U.S. citizens visit an ED each day for recreation related injuries. ${ }^{2}$ Recreational cricket players averaged an injury incidence of 2.3 per 100,000 in New Zealand between 2000 to $2005 .{ }^{44}$ Sport club participation was the strongest predictor of injury for 5,889 hospitalized Finn's, where $23.9 \%$ of injuries were knee or shin related. ${ }^{6}$ Twenty-seven percent of adults and $60 \%$ of children participate in community-based athletic activities across Australia. ${ }^{42}$ Despite the information provided on injury epidemiology across the collegiate club sport population, more research is needed.

Athletes, especially club sport athletes, are continuously seeking methods to improve performance and reduce risk of injury. ${ }^{27,38}$ To do so, athletes will train to build strength and increase speed. Unfortunately, injury prevention and recovery techniques are frequently given less priority despite the ability to potentially prevent injury. ${ }^{6,39}$ As a result, athletes can develop compensatory movement patterns in an attempt to meet the demands of higher performance. 
Performing at higher levels adds fitness to dysfunction when executing inefficient movements. ${ }^{7-}$

${ }^{11}$ Over time, these deficiencies can lead to injury. Common injury prevention and recovery techniques include stretching, ice baths, foam rolling, therapeutic modalities, and rest. ${ }^{43}$ Unfortunately, these techniques do not identify musculoskeletal limitations. Thus, implementing functional movement screening can provide an assessment of a club sport athlete's movement efficiency to help prevent injury. ${ }^{30}$

In order to assess and correct dysfunction, movement screens should be incorporated into pre-participation screening. Cook and colleagues ${ }^{7-11}$ developed the Functional Movement Screen (FMS) to bridge pre-participation screening and performance testing. This tool is designed to examine functional movement patterns. The FMS is used to develop individualized, functional interventions to establish a benchmark for functional movement improvement. It is important to understand that the FMS was designed with the goal of determining movement competency. ${ }^{7-11}$ Seven movements comprise the FMS: the deep squat, hurdle step, inline lunge, shoulder mobility, active straight leg raise, trunk stability push up, and rotary stability. ${ }^{7-11}$ Each movement is scored from zero to three. ${ }^{7-11}$ Zero is assigned to a movement if the patient experiences pain. ${ }^{7-11}$ A score of three identifies an ideal movement pattern without deficiencies, limitations, or compensation patters. The total score of the seven movements is called a Composite Score (CS) ${ }^{7-11}$ The average FMS CS is $14 .{ }^{7-11}$ Fourteen also serves as the cutoff score. In other words, it is conceived that individuals who score $\leq 14$ are at a greater risk of injury. ${ }^{7-11}$ The score from the initial screening serves as a baseline. The baseline dictates what program should be implemented to address weaknesses. Comparing the baseline to reassessments exhibits progress with movement competency and improved movement scores. Despite the original intent of the FMS screen to detect movement pattern deficiencies, 
recent studies have begun to focus on injury risk and performance with collegiate athletes. Fiftynine 59 NCAA Division I American football players had FMS scores compared with knee strength, hip strength, and various hop performance tests. ${ }^{45}$ Correlation of the FMS with performance measures was not evident. ${ }^{45}$ The association between 37 Division I rowers' FMS scores and injury occurrence was examined as poor. ${ }^{13}$ Low FMS Composite Scores (CS) were more likely to predict low back pain. ${ }^{13}$ An examination of 195 Division I student-athletes' FMS CS were not significantly different between injured and non injured groups, $14.3+2.5$ vs.

14.1 $+2.4 .{ }^{36}$ Overall, studies using the FMS with a collegiate population commonly assessed and correlated CS with performance measures or injury.

After reviewing collegiate and high school FMS studies, studies examining different active populations are minimal. ${ }^{41-45}$ College students participating in club sports have not been examined with the FMS. Despite the higher level of competition in college athletics, numerous college students still participate in intense physical activity through club sports. ${ }^{41-45}$ Copious hours are dedicated to training, practice, and competing. ${ }^{41-45}$ As participation numbers rise, there is a need for tools to screen those at risk for injury. Unfortunately, club sport athletes do not receive the same level of care as varsity collegiate athletes. ${ }^{41-45}$ These individuals still perform explosive maneuvers, feats of strength, and push through the pain of training and injury. ${ }^{41-45}$ As the volume and history of participation increase, there is a greater likelihood for musculoskeletal asymmetries and limitations to develop. ${ }^{41-45}$ Inefficient movement patterns during activity will cause asymmetries and limitations.

Compared to varsity collegiate athletes, the remainder of the active college student population receives less attention to musculoskeletal assessments. There is a lack of studies supporting the need to examine the collegiate club sport student-athlete population. Most studies 
using the FMS assess varsity collegiate athletes or tactical professionals to measure injury risk, performance, validity or reliability. Without proper neuromuscular control and functional movement patterns, the collegiate club sport student-athlete is at a greater risk of injury. Poor training techniques and compensatory movement patterns can lead to acute or chronic injuries. The FMS is needed to detect deficient movement patterns in the club sport setting, especially field club sport athletes. This is necessary to create an individualized intervention. Therefore, research is needed to support the implementation of the FMS among collegiate club sport student-athletes. Furthermore, there is little on field club sport athletes, let alone if years of experience and hours practicing affects FMS composite and individual scores.

Overall, no screening tool exists to assess the quality of functional movement among collegiate club sport student-athletes. The physical demands of these individuals has not been thoroughly assessed in the literature. There is no information regarding the application of the FMS and its utility with this population. It is evident that athletic injuries can have long-lasting detriments to participation, and can be potentially be prevented with an intervention. ${ }^{7-11}$ In order to match the rise of collegiate club sport student-athletes and number of associated injuries, there must be an implementation of injury prevention programs. The FMS can serve as useful, efficient tool to assess the areas of musculoskeletal asymmetries and limitations that can cause an injury associated with physical activity. ${ }^{7-11}$ There is lack of information regarding collegiate club sport student-athletes and how they score on the FMS. Thus, collegiate club sport studentathletes are expected to have a FMS CS of $14 .^{7-11}$ Therefore, the following research questions were asked:

Research Questions

1. What are the FMS CS's among collegiate field club sport student-athletes? 
2. What is the average FMS CS of collegiate field club sport student-athletes?

3. Do collegiate field club sport student-athletes score higher than the 14 point cutoff?

4. Which of the seven movements will collegiate field club sport student-athletes score lowest?

5. Which of the seven movements will collegiate field club sport student-athletes score highest? Experimental Hypotheses

1. The average FMS CS will be 14 .

2. Individual movement scores will be highest in the hurdle step.

3. Individual movement scores will be lowest in the rotary stability.

4. Collegiate field club sport student-athletes with $\geq 10$ years of participation in their sport will have a lower FMS CS in comparison to those with $<10$ years.

5. FMS CS will be lower in those who spend $\geq 12$ hours per week spent practicing, training, and competing in comparison to those who spend $<12$ hours per week.

Assumptions

1. All subjects will meet the inclusion criteria for the research study.

2. The FMS is a valid and reliable screening tool.

3. Documentation of FMS scores will be accurate.

4. Participants will complete each FMS movement to the best of their ability.

Delimitations

1. Subject population is specific to only collegiate field club sport student-athletes.

2. This study is not generalized to other age groups than a population aged 18-23 and to one college campus.

Operational Definitions

1. Collegiate Club Sport - a registered student organization formed by individuals with a common interest in a sport and/or recreational activity that exists to promote and meet regularly to pursue and develop interest within a defined scope. ${ }^{49}$

2. Collegiate Field Club Sport Student-Athlete - a full-time student committed to and currently 
participating in a non-varsity sport that plays on a field at a Mid-Atlantic university, through the club sports program.

3. Functional Movement Screen (FMS) - A set of seven physical movements that assess mobility, strength, and coordination to determine an individual's compensation patterns and/or deficiencies in movement patterns. The battery of movements illustrates an individual's ability to progress to more difficult tasks. ${ }^{7-11}$

4. Functional Movement Screen Composite Score (FMS CS) - a subject's total score of the seven movements performed in the FMS. ${ }^{7-11}$

5. 10 Years - number of years the athlete has been participating in their sport, beginning between the ages of 8-13, assuming that middle school students have the opportunity to participate..

6. 12 Hours - an average of two hours per day spent practicing, training, or competing across six days in a week, with the seventh day as a rest day.

\section{Limitations}

1. Non-certified FMS instructor.

2. Participants may not want to participate in data collection.

3. Threats to internal and external validity.

4. Participants may experience muscle soreness or fatigue at the time of screening from practices, competitions, and training.

5. The type and duration of activity will be dependent on the sport of the participant.

Significance of Study

The importance of living an active lifestyle has increased as obesity rates and other health complications rise. College students will participate in club sports to fulfill their need for exercise and continue the passion for that sport. As the number of active individuals rise, so will the number of musculoskeletal injuries.

The importance of this research is to apply the FMS to a population that has not previously been examined: collegiate club sport student-athletes. Although the number of hours spent training for activity may be less than a varsity athlete, compensatory movement patterns 
can negatively impact performance and ability to continue participation if injury occurs. The screening tool will be used to collect FMS CS's, generalizing how this population scores and areas of deficiency. Number of years participating in the sport and hours of activity per week will also be accounted for.

From the perspective as a practitioner, this will provide introductory data to establish baseline FMS composite scores among this population. These data can be used to help these individuals continue the desire to compete, remain active and live a healthy lifestyle. Athletic trainers and strength and conditioning coaches will be able to implement this information into practice by establishing the most effective interventions. The objective of a movement screening for club athletes is to determine inefficient movement patterns so an appropriate intervention can be developed. The sports medicine professional or strength and conditioning coach can further expand the utility of these findings and interventions to potentially decrease injuries, increase performance, and restore musculoskeletal symmetry and range of motion. Club sport athletes will benefit from the FMS based on the intervention developed to address the asymmetries and limitations that were discovered.

After this study is completed, the goal will be to share this information with athletic trainers and other sports medicine professionals working with the collegiate club sport studentathlete population. This will aim to persuade other athletic trainers to implement the FMS to decrease risk of injury, increase performance, and improve quality of life. This will be accomplished through an individualized intervention to restore functional movement patterns. Athletic trainers can also use this information to educate athletes about the importance of quality movement and how to improve from baseline. This should help facilitate decision making and critical thinking on rehabilitation program design, pre-participation exams and performance 
enhancement. As this study being the first in this concentration, it will create awareness for further research. The findings of this study will be shared with current classmates and future colleagues. Information will be disseminated through workshops and seminars at local universities. 


\section{APPENDIX B}

\section{LITERATURE REVIEW}

Introduction

The popularity of collegiate club sports has grown through the desire of student athletes pursuing a passion for sport. ${ }^{46}$ Of all the club sports teams available, field sports such as rugby, lacrosse, and soccer have experienced an increase in popularity at the collegiate club sport level. ${ }^{4,38,46}$ Unfortunately, these athletes do not have the same commitment and access to resources compared to varsity collegiate athletics. Varsity collegiate athletes, substantially in NCAA Division I, have significantly more access to sports medicine, head coaches/assistant coaches and strength and conditioning professionals. ${ }^{4,46,47}$ Because of this, poor movement skills are common in college club sports. ${ }^{46}$ Poor movement skills can lead to musculoskeletal asymmetries and limitations, creating functional movement deficits.

Implementing a functional movement assessment is equally important for collegiate field club sport and varsity athletes. The Functional Movement Screen (FMS) is designed to assess movement asymmetries and limitations. ${ }^{19,38}$ An individualized, corrective intervention is developed to address these abnormalities. ${ }^{19,38}$ Research on this topic would produce a functional movement profile for this unique population. The following topics will be addressed in the literature review: Collegiate Club Sport, Epidemiology, Functional Movement Screen, Seven Movement Components, Reliability, Validity, and Functional Movement Screen Composite Scores In Field Sports.

Collegiate Club Sport

A collegiate club sport is a registered student organization formed by individuals with a common interest in a sport and/or recreational activity that exists to promote and meet regularly 
to pursue and develop interest within a defined scope. ${ }^{49}$ As collegiate club sports lack a nationally governing body, responsibility and organization for the team is directed by the players. ${ }^{47,49}$ Approximately two million college students participate in club sports across the United States. ${ }^{47}$ In contrast, there are 430,000 student-athletes participating in sports governed by the National Collegiate Athletic Association (NCAA). ${ }^{47}$ Throughout the years, participation in club sports has continued to grow. ${ }^{36}$ For example, club volleyball grew from twenty teams and 206 male athletes to 258 teams and 2,806 athletes in twenty years. ${ }^{47}$ In 2008 , the collegiate club soccer championship included seventy-five teams and 1,380 players. ${ }^{47}$ Despite the surge in participation, collegiate club sport athletes do not receive the same benefits as varsity athletes, including medical staff, strength and conditioning, locker rooms, and larger budgets. ${ }^{4,46,47}$ There is also a lack of crowd support, adult leadership, and financial assistance from colleges. ${ }^{4}$ Epidemiology

As participation has grown in collegiate club sports, especially field sports, the reporting of injuries is not as prevalent. ${ }^{27,40}$ Often times the injury rates for club sports are interpolated from club sports in other countries and from the NCAA. ${ }^{47}$ Of the collegiate field club sports, lacrosse, rugby and soccer appear to present the most injuries. ${ }^{49}$

Collegiate female lacrosse players experienced 3392 injuries from $1988-2004 .^{51}$ Of those injuries, $60 \%$ occurred to the lower extremity, ${ }^{51}$ with $22.6 \%$ ankle sprains. ${ }^{51}$ Contact was the most common mechanism of injury. ${ }^{51}$ Ten men's lacrosse players experienced an injury at Utah State University in a five year span. ${ }^{42}$ Youth lacrosse players (nine to fifteen years old) experienced 6.3 injuries per 1,000 athlete-exposures (AE). ${ }^{3}$ An athlete exposure is defined as one athlete participating in one game where there is the possibility of an injury. ${ }^{3}$ Contusions and lacerations were most commonly reported (12.3 injuries) while dislocations, fractures, strains, 
and sprains were less frequent (7). ${ }^{3}$ The high prevalence of contusions and lacerations is most likely the result of permissible stick and body checking. ${ }^{3}$ Plus, the most common mechanism of injury reported was body-to-body contact. ${ }^{3}$ An athletic trainer was present at each competition, providing assurance that all injuries were reported. However, these injury rates are low since this study included one recreation league across one season. ${ }^{3}$ A comparison of youth versus young adult lacrosse injury epidemiology should be completed to determine if age, experience, and rules play a factor with injury occurrence.

Eight hundred and ten female collegiate rugby players experienced a knee injury rate of 1.3 per $1,000 .^{53}$ Twenty-one anterior cruciate ligament ruptures accounted for 0.36 per $1,000 .^{53}$ 129 female and 240 male intercollegiate club rugby players experienced 659 injuries during a five year surveillance. ${ }^{4}$ The incidence of injury was $30 \%$ higher in males. ${ }^{4}$ Injuries to the head and shoulder were more common in males (163 head, 60 shoulder male injuries vs 47 head, 27 shoulder female injuries). ${ }^{4}$ Injuries for females were evident more in the lower extremity (9 female vs 3 male ACL injuries). ${ }^{4}$ It is suggested that injury rates among matched sports are similar, but the patterns may differ. ${ }^{4}$ Unlike most collegiate club rugby teams, these athletes had access to superb facilities, a paid coaching staff, and medical personnel with experience in rugby. ${ }^{4}$ Future studies should examine the average college club rugby teams that do not have the same access to facilities and coaching staff.

12,974 collegiate male soccer injuries were reported between 1988-2003. ${ }^{5}$ Ankle injuries were most prevalent with 1,138 incidents. ${ }^{5,39}$ Certified athletic trainers reported 1524 high school soccer injuries across 637,446 AE's, with an injury rate of 2.39 per $1,000 .^{60}$ During a five year span, thirteen male soccer club athletes sustained an injury at Utah State University. ${ }^{52}$ The injury rate was greater during competition (4.77) than practice $(1.37) .{ }^{50}$ Sprains $(26.8 \%)$ and strains 
(17.9) were the most common injuries reported. ${ }^{50}$ The ankle $(23.4 \%)$ and knee $(18.7 \%)$ were most frequently injured. ${ }^{50}$ Female soccer players experienced ligaments ruptures at a rate of 26.4 per 100,000 AE's. ${ }^{50}$ The rate for male soccer players was $1.98 .^{50}$ The study does not discuss if players were involved in strength and conditioning programs or functional movement interventions. Depending on the demographics where the soccer athletes were recruited could determine the resources available. Soccer players in wealthier communities would most likely have access to athletics trainers and strength and conditioning coaches compared to those in poorer neighborhoods.

\section{Functional Movement Screen}

High injury rates have encouraged athletic trainers and strength and conditioning coaches to use various methods to assess for risk of injury. ${ }^{13,14}$ These practitioners have implemented movement screening tools to assess for risk of injury. ${ }^{13,14}$ The FMS has commonly been used as an injury predictor in the literature. ${ }^{13,14}$ Screening tools are not designed to quantify risk of injury. ${ }^{13,14}$ Screening tools, like the FMS, are designed to assess musculoskeletal asymmetries and limitations displayed during functional movement patterns. ${ }^{7-11,13,14}$

The Functional Movement Screen (FMS) was developed to assess musculoskeletal asymmetries and limitations. ${ }^{7-11,19}$ Seven movement patterns are used in the FMS: the deep squat, inline lunge, hurdle step, shoulder mobility, active straight leg raise, trunk stability push-up, and quadruped rotatory stability. ${ }^{7-11}$ These movements are everyday functions that are designed to expose asymmetries and limitations. Each movement is scored on a scale of 0-3, with 3 being a perfect execution. ${ }^{7-11}$ A score of zero is given if pain is experienced during the movement. Composite scores (CS) range from 0-21..$^{7-11,15,16,19}$ 
In the 1990's, the term functional was popularized and defined as exercises that best replicated natural movement patterns in activities of daily living and sport. ${ }^{12}$ Functional mobility and postural stability are requirements for athletic performance. ${ }^{12}$ The FMS was originally developed to serve as an inexpensive, simple screening tool for functional movement quality. ${ }^{12}$ The seven movements were selected to recreate the demands of athletic performance and activities of daily living. ${ }^{12}$ There are four core purposes to the FMS. First, the FMS can identify areas of deficiency that have the potential for future injury. ${ }^{7-11,15,16}$ Second, the FMS can be used to develop corrective exercise interventions based on the asymmetries and limitations discovered. ${ }^{7-11,15,16}$ Third, this tool serves as a baseline for improvement and progress through the corrective exercise intervention. ${ }^{7-11,15,16}$ Lastly, the FMS can be referenced for future clinical decisions..$^{711,15,16}$ Recently, the research has exhibited a shifted focus away from the original intent of the FMS. ${ }^{12}$ Newer studies have examined the relationship of the FMS with athletic performance measures and injury incidence. ${ }^{12}$ However, few studies found significant data to suggest implementing the FMS for a different purpose. ${ }^{12}$ Therefore, it is important to not perceive the FMS as a diagnostic tool. The end goal is to establish a movement profile that is unique to the individual.

\section{Seven Movement Components}

The seven movements of the FMS are designed to assess mobility and stability through the kinetic-chain. ${ }^{7-11,15,16}$ Mobility is defined as the freedom of movement around a joint..$^{7-11,44 \text {, }}$

${ }^{45}$ Stability is the strength, coordination, and control around a joint. ${ }^{7-11,44,45}$ Mobility and stability have an inverse relationship. ${ }^{7-11,13}$ Greater mobility results in less stability. ${ }^{7-11,13}$ Examples are the ball and socket joints of the shoulder and hip. ${ }^{14}$ The shoulder is known for having greater mobility, but less stability. ${ }^{14}$ On the contrary, the hip has significant stability but 
less mobility. ${ }^{14}$ Both are necessary to create efficient movement patterns. Thus, the seven movements demand a combination of stability and mobility to be performed correctly. ${ }^{711,13}$

The deep squat is a closed kinetic-chain exercise requiring dorsiflexion of the ankles, and flexion of the knees and hips to eccentrically move to a sit-down position. ${ }^{7-11,44,45}$ Simultaneously, extension of the thoracic spine, and flexion, abduction, and external rotation of the shoulders is necessary to maintain an upright torso throughout the movement. ${ }^{7-11,44,45}$ Poor performance on the deep squat can reveal deficiencies in the upper and lower extremity. A lack of dorsiflexion or hip flexion can limit the individual's mobility. Plus, a lack of thoracic extension and shoulder mobility can result in deficient movement patterns. A lacrosse goalie must be able to squat and quickly move the arms to catch a ball. A goalie must have the required hip, knee, and ankle flexibility with thoracic and scapular mobility to react to the incoming ball. The overall goal of the deep squat is to assess the functional mobility of the hips, knees, ankles, shoulders, and thoracic spine bilaterally. ${ }^{7-11,44,45}$

The hurdle step is performed unilaterally and assesses stride mechanics and stepping efficiency. ${ }^{7-11,44,45}$ One leg must maintain dynamic stability and balance as the other leg moves over the hurdle. This movement primarily focuses on the coordination and stability of the hips, knees, and ankles with stepping and single-leg balance..$^{7-11,44,45}$ The moving leg requires mobility of the hip, knee, and ankle. The stationary leg must stabilize itself as the other leg moves. These requirements match the demands necessary to run and kick a ball. Both movement patterns need one closed-kinetic chain leg to maintain balance and dynamic stability as the openkinetic chain leg prepares to make contact with the ground or ball. Proficiency in this movement requires coordination in the open kinetic-chain of the stepping leg while maintaining closed 
kinetic-chain stability on the balancing leg. Therefore, the hurdle step requires dynamic stability, balance, coordination, and mobility of the lower kinetic-chain. ${ }^{711,44,45}$

Next, the in-line lunge is used to recreate unilateral, sport specific movement patterns such as rotation, deceleration and lateral movement. ${ }^{7-11,44,45}$ The individual must maintain stability of the trunk and extremities to prevent rotation. The stance leg must have adequate ankle, knee, and hip stability and closed kinetic-chain abduction. Hip abduction, ankle dorsiflexion, and rectus femoris stability and flexibility are required for efficient execution. Agility and cutting in soccer or lacrosse have similar demands to those with the in-line lunge movement. This poses a great challenge to mobility and stability, as well as balance.

Prior to performing the shoulder mobility movement, a clearing test must be performed. The individual will place the hand on the opposite shoulder and raise the elbow upwards. If pain is experienced, a score of zero is given. Shoulder mobility assesses movement at the glenohumeral and scapulothoracic joints, and the thoracic spine. ${ }^{711,44,45}$ One arm is placed into extension, internal rotation and adduction as the opposite arm moves into flexion, external rotation and abduction. Overhead athletes will display greater external rotation, resulting in decreased internal rotation. Individuals with rounded shoulders are commonly affected by tight pectoralis minor and latissimus dorsi muscles. Plus, scapulothoracic deficiencies will limit glenohumeral mobility. Quality execution of this movement is important for overhead throwing athletes, such as lacrosse players. ${ }^{7-11}$ The shoulder mobility test requires opposite arm motion, similar to lacrosse stick throw. ${ }^{7-11}$ Overall, the shoulder mobility emphasizes examining the kinetic chain and understanding how distal segments can be affected by proximal limitations. ${ }^{7-11 \text {, }}$ 44,45 
The active straight leg raise requires a stable torso as the athlete lies supine and raises the lower extremity ipsilaterally. ${ }^{7-11,54,55}$ This movement assesses flexibility of the hamstrings and gastrocnemius along with core and pelvic stability. The leg on the ground must maintain a neutral position. ${ }^{7-11,44,45}$ These requirements mimic the demands to kick a soccer or rugby ball. The plant leg must maintain stability and balance as the kicking leg has adequate hamstring and gastrocnemius flexibility. Both legs are in extension throughout the movement. Limitations imposed by the hamstrings and iliopsoas will negatively affect hip mobility. ${ }^{7-11,44,45}$

A spinal extension clearing exam is performed prior to the trunk stability push-up. The individual will press up on the hands, allowing the low back to extend. A score of zero is given when pain is noted. The test functions similarly to the cobra movement. The trunk stability pushup tests an individual's ability to move the body as a unit through effective core and spine stabilization..$^{7-11,50,54,55}$ Inadequate stability will lead to a loss of kinetic energy resulting in decreased performance and potential for injury. ${ }^{7-11,54,55}$ A transfer of energy occurs through the trunk from the upper to lower extremity and visa versa. ${ }^{7-11}$ This transfer occurs as the ball is released from a lacrosse player's stick or the rugby ball is propelled from the athlete's hands. This closed kinetic chain exercise moves through all three planes of motion. ${ }^{7-11,54,55}$

Before the movement is performed, a spinal flexion clearing test is conducted to determine if pain is elicited. ${ }^{7-11,54,55} \mathrm{~A}$ score of zero is given when pain is noted as the low back flexes in a child's pose position. The rotary stability movement challenges coordination and energy from different body segments through the torso. Opposing lower and upper extremity motion is combined to assess multi-planar trunk stability. ${ }^{7-11,54,55}$ The transfer of forces when an athlete decelerates, stops, and accelerates in a different direction represents the transfer of forces 
and stability assessed in the rotary stability movement. Lacrosse, soccer, and rugby demand transfer forces and stability during sprinting and changes in direction.

Reliability

The FMS has displayed moderate to strong test-retest and interrater reliability. Examiners such as physical therapists, athletic trainers and strength and conditioning coaches are proficient at assessing patients' limitations and asymmetries. A common limitation among studies examining reliability with the FMS is the use of videotaped analyses. The examiners analyze and grade videos of the subjects performing the seven movements. ${ }^{46}$ Videotaped analyses provide convenience for the viewers, but do not provide the same perspective as a real-time analysis. Real-time analyses are superior because they are closer to how the FMS will be conducted in practice. An improved method to assess reliability is to conduct a real-time analysis to better replicate how the FMS would be used in the field. Additionally, video viewing was permitted at $1 / 2$ speed with unlimited reviews. ${ }^{47}$ This form of observation is not possible or realistic in a realtime analysis. An athletic trainer using the FMS for a football team does not have time to perform an unlimited number of movement repetitions or view a slower version for each of the seven movements. Subsequently, scoring of each movement must be efficient. In a video analysis, there is no pressure on the examiner. An examiner performing a real-time analysis must score the movement immediately after completion and then move onto the next movement or patient. Furthermore, a video analysis is limited to the frame and angle to which it was filmed. In a real-time analysis, a 3-D view is available so that the examiner is free to move in any position around the patient to obtain an accurate score.

Despite this, it is still evident that videos are used to assess the FMS. ${ }^{22,36,37,58,59}$ Tafuri et al. ${ }^{49}$ allowed raters to score participants by watching videos, rather than a real-time analysis. ${ }^{49}$ 
There was also no limit to the number of replays each rater could view. ${ }^{59}$ The four raters achieved an interclass correlation coefficient (ICC) of 0.882 , which is similar to other studies conducted whose ICC's were $0.971,0.87-0.89$ and $0.92-0.98 .^{22,36,37,58,59}$ Significant ICC scores range from $0.75-1.0$, indicating a strong correlation. These significant scores could be a result of video analyses. A real-time analysis would better replicate how the FMS is conducted in practice, and potentially exhibit lower interrater reliability. It is important to acknowledge that strong reliability was noted between FMS CS, not individual movement scores. ${ }^{59}$

In comparison, athletic trainers watched and scored three different videotaped models. ${ }^{45}$ This procedure is a better way to evaluate reliability compared to a study that performed the second video viewing the same day and did not include randomization. A moderate ICC of 0.754 was found after analyzing all raters. ${ }^{45}$ Despite a high ICC of 0.906 , raters watched videos of each screen at $1 / 2$ speed with unlimited views. ${ }^{47}$ The study also did not include shoulder mobility, one of the seven movements of the FMS ${ }^{47}$ Both of these procedures could lead to inaccurately high ICC's that misrepresent reliability of the FMS.

In the future, researchers should conduct a study assessing test-retest and interrater reliability while comparing video versus real-time analyses. For example, 10 clinicians that are experienced with the FMS watch and score videos of five different patients. These patients are then randomized. Each clinician will then perform a real-time analysis for every patient. An ICC will be conducted to compare the consistency of clinicians within and across both forms of analysis. Overall, this type of study is not convenient and has greater time requirements, but may aid in the development of future studies to illustrate which practices to follow when examining the reliability of the FMS. Plus, it is not practical to assume all practitioners have access to video 
analysis technology and time where multiple reviews can be examined for movement deficiencies.

A clinician's level of experience using the FMS is an important factor to consider when measuring reliability. It has been concluded that reliability will improve as the clinician's training increases. ${ }^{52}$ Three groups of athletic training students, athletic trainers, and athletic trainers with a minimum of six months experience using the FMS were studied. ${ }^{35}$ The groups without six months of experience were novices and had little to no experience or knowledge of the FMS. ${ }^{35}$ Three subjects were recruited from the university community to be models for video analysis. ${ }^{35}$ Video analyses were repeated one week later, including video randomization. ${ }^{45}$ No details were provided in regards to activity level, previous injury and subject recruitment. A moderate ICC of 0.754 was found after analyzing all raters. ${ }^{35}$ The athletic trainers with experience had the strongest ICC, followed by the athletic trainers and athletic training students. ${ }^{45}$ In contrast, a comparison of average individual movement scores between trained versus untrained raters illustrated an excellent level of agreement for most of the functional movements. ${ }^{46}$ Interrater reliability was examined between two experts and two novices by assessing forty college students. ${ }^{46}$ The weighted Kappa statistic measured agreement between the two groups' scores. ${ }^{46}$ All students were recruited by word of mouth, and thirteen were varsity athletes. $^{46}$

Some studies examined the reliability of the FMS and included clinicians that had formal training or certification. Interrater reliability was measured between three novice and one expert rater. Each novice was certified in FMS scoring. ${ }^{59}$ The expert had formal training before the certification was established and had 3 years of experience. ${ }^{50}$ The average ICC was $0.882 .{ }^{59}$ In contrast to Tafuri et al., ${ }^{50}$ an ICC of 0.906 was calculated among 20 untrained physiotherapists 
using the FMS to assess five squash athletes. ${ }^{47}$ The untrained raters exhibited higher interrater reliability compared to the trained novice raters. ${ }^{47}$ Further, eight novice physical therapy students in the second or third semester of the program were recruited. ${ }^{50} \mathrm{~A}$ unique feature to the methods was requiring the physical therapy students to go through twenty hours of FMS training with four physical therapists and one research assistant. ${ }^{50}$ The training established standardization and created more consistency among each rater. Since these novices received training to use the FMS, this could lead to skewed scores compared to those without any prior training. However, an ICC of 0.74 , indicating a moderate level of reliability was reported.$^{50}$ In contrast, athletic training students reported low ICCs of $0.372 .{ }^{45}$ This can be related to the athletic training students having little to no experience using the FMS. It can be concluded that more training and experience positively influences ICC scores. Thus, FMS scores with moderate to strong testretest reliability may relate to training and experience with the FMS..$^{51}$ Plus, the FMS has strong interrater reliability when examiners are credentialed. ${ }^{51}$ Reliability decreased as experience using the FMS and clinical experience were limited. ${ }^{51}$ Experience positively influences test-retest reliability with the FMS. ${ }^{51}$

Validity

The FMS is a quick, inexpensive screening tool that is easy to administer. ${ }^{, 711,14,54,55}$ As a result, popularity is evident among athletic trainers, physical therapists and strength and conditioning coaches. Recently, the research has exhibited a shifted focus away from the original intent of the FMS. ${ }^{12 .}$ Thus, clinicians are using the FMS beyond the intended use. The majority of studies focused primarily on injury prediction and performance. ${ }^{53}$ As previously discussed, the intended purpose of the FMS is to identify areas of limitation, guide corrective exercise program development, serve as a baseline for functional movement, and act as a clinical decision tool in 
readiness for return to play. Few studies exist that measure the FMS validity to assess the intended purpose.

Validity studies included effectiveness of training and intervention programs, and risk and prediction of injury and athletic performance. Although these uses may be interpreted similarly to assessing how an intervention impacts an individual's asymmetries and limitations, there are different goals behind each purpose. In order to determine if the FMS can be implemented for other purposes, validity must be examined. A consistent screening tool is purposeless if it does not measure what it is intended to measure.

The results from the FMS are intended to develop a corrective exercise intervention for asymmetries and limitations. ${ }^{7-11,54,55}$ Training programs are intended to neutralize the effects of poor habits, which may cause a lack of change in posttest scores. It is difficult to prevent the cause of asymmetries and limitations. Future research could aim to control the causes of musculoskeletal asymmetries and limitation and implement the training or intervention programs simultaneously. It may difficult to remove a subject from the environment causing the asymmetries and limitations, especially if it is in the workforce. An alternative would be to modify the activity to promote better posture and function. Only one study was found assessing the ability of the FMS to serve as a benchmark for improvement in functional movement after an intervention. The goal was to use the FMS as a means to evaluate changes before and after a fitness-oriented or movement-oriented exercise intervention. ${ }^{15,16}$ A 12 week intervention was developed for 60 firefighters. ${ }^{15,16}$ The firefighters were divided into three groups: movementoriented, fitness-oriented or control group. ${ }^{15,16}$ The Wilcoxon signed-rank test was used to measure changes in the post-training assessment. ${ }^{15,16}$ Pretest results displayed similar FMS CS across groups. ${ }^{15,16}$ The post-tests scores demonstrated insignificant changes in FMS CS. ${ }^{15,16}$ 
Thus, it was concluded that important factors that could lead to a lack of change in FMS scores are the daily routines and habits that cause a firefighters' asymmetries and limitations. ${ }^{15,16}$

The FMS has been used as an injury predictor because it assesses asymmetries and limitations. ${ }^{13,53}$ Those who have lower FMS CS are thought to be at a higher risk of injury. ${ }^{7-11,}$ ${ }^{13}$ A FMS CS $\leq 14$ is hypothesized to identify individuals that are at a greater risk of injury. A significant limitation is determining a consistent definition of injury. A systematic review included nine studies that found individuals who scored $\leq 14$ were 2.74 times more likely to sustain an injury. ${ }^{56}$ The diverse participant pool included NCAA Division I and II athletes, Coast Guard cadets, professional football players, major junior hockey players, and fire fighter trainees. The studies included defined injury as "missed time" or "required medical attention". 56 In contrast, another systematic review concluded the FMS is not a valid predictor of injury. ${ }^{47}$ One study defined an injury as "causing the athlete to be placed on the injury reserve for at least three weeks. $^{45,47}$ The lack of consistency in defining injury could contribute to the FMS inability to predict injury. The authors claimed that the studies included were also low quality and contained threats to validity. ${ }^{57}$. Both systematic reviews only examined studies that had a level of evidence of three. A third review ${ }^{48}$ also found varying definitions for injury. There was an equal split of individuals who sustained an injury that scored above fourteen or fourteen or less. ${ }^{48}$ Definitions for injury included "training related injury resulting in time loss for four weeks" and "injuries related to training and requiring three consecutive days of missed training" ${ }^{48}$ Further research is needed to determine if the FMS can accurately predict injury. ${ }^{56-58}$

A significant concern regarding the ability of the FMS to predict risk of injury is the type of injuries included in previous studies. The FMS is used to assess musculoskeletal asymmetries and limitations ${ }^{.7-11}$ Thus, it is imperative to focus on musculoskeletal injuries that are caused by 
movement deficiencies. ${ }^{13}$ Including injuries beyond the musculoskeletal system would not assess asymmetries and limitations, skewing the results. Eye injuries, concussions and other contact injuries are not the result of movement deficits.${ }^{13}$ Plus, the rate of non-contact versus contact injuries should be compared. ${ }^{13}$ It is hypothesized that the FMS can identify those who sustained non-contact injuries. Future studies should indicate if the injury was non-contact. Contact injuries are not conclusively the result of asymmetries and limitations, but from high forces and velocities upon impact.

Another concern when assessing risk of injury are the participant populations studied. There are several factors that determine an individual's risk of injury, such as type of activity, occupation, age, and weight. ${ }^{48}$ It is difficult to determine if the FMS can measure risk of injury when different populations are examined. ${ }^{48}$ Previously mentioned studies reviewed athletes participating at the professional, NCAA Division I and II, and high school level, along with firefighters, police officers, military personnel, and clinic patients. ${ }^{56-59}$ In one study, ${ }^{64} 1,113$ adults were screened, averaging a FMS CS of 13.7. In the secondary school setting, four experienced examiners with FMS certifications recruited and scored 167 high school athletes. ${ }^{13}$ The average FMS CS for un-injured student-athletes was $13.11 \pm 1.69$ versus $13.00 \pm 2.32$ for injured student-athletes. ${ }^{13}$ The researchers concluded this difference insignificant. ${ }^{13}$ Plus, the inline lunge movement displayed better scores for the injured student-athletes. ${ }^{13}$ Twenty patients with chronic ankle instability scored significantly lower than the control group. ${ }^{59}$ Although, only functional movements that involved the lower extremity were included.$^{59}$ When 290 elite athletes from the Chinese national teams were evaluated, an average FMS CS score of $15.2 \pm 3.0$ was noted. ${ }^{60}$ One review suggested there is moderate evidence that the FMS CS predicts injury in soccer athletes, but limited or conflicting evidence with American football, college athletes, 
basketball, ice hockey, running, police, and firefighters. ${ }^{61}$ Each population displays different FMS CS. ${ }^{61}$ The demographics, physical demands, and fitness level of a professional football player are not similar to a firefighter. A suggestion would be to establish a cutoff FMS CS for each active population to best predict injury risk.

There is concern that using the FMS CS to predict injury risk is misleading. ${ }^{71}$ It is hypothesized that clinicians should pay more attention to individual movement scores. ${ }^{60}$ Similar mean and standard deviations for FMS CS are found across studies examining athletes $(14.3 \pm 1.8,15.6+1.5,11.8+1.8,13.3 \pm 1.9,14.8+2.4,16.3 \pm 2.4,15.4+2.8,15.8+1.8,16.2 \pm 1.9$, 12.6 \pm 3.7$).{ }^{\mathrm{Yi}, 19,45,62}$ An assessment of 301 elite junior Australian football players displayed sixty percent of players scored at or below fourteen, with thirty-eight percent of players experiencing at least one or more painful movements. ${ }^{63}$ Only examining the FMS CS can hide a specific area of concern. Individual scores should be examined separately to determine if the painful movements result in injury. A comparison of young, active males and females illustrated insignificant differences in FMS CS, but significant differences across the inline lunge, deep squat, hurdle step, and active straight leg raise ${ }^{58}$ Further research is needed to determine if individual movement scores are a stronger predictor of injury.

A limitation to assessing athletes can be skill level and playing time. ${ }^{13}$ It is inferred that those with higher skill levels have better movement patterns. ${ }^{13}$ Thus, they are presumed to have higher FMS CS. ${ }^{13}$ Those with higher skill levels are more likely to receive more playing time. ${ }^{13}$ The more exposure time on the field, the greater the risk for injury. Exposure time could have a significant influence on the relationship between FMS CS and predictor of injury. It is difficult to establish this relationship when there are many factors that impact injury rates. Future studies could include an examiner recording amount of playing time. 
It may be beneficial to establish an average FMS CS for each active population to develop an individual cutoff score. Further research is needed to suggest that the FMS is a valid injury predictor across varying active populations. Overall, significantly more research must be conducted to determine if the FMS is a valid predictor of injury.

Finally, the FMS has been used as a predictor of athletic performance. ${ }^{15,16,65}$ However, the performance measures examined vary across studies and sports. The selection of performance measures should replicate the demands for specific active populations. Twenty-five Division I golfers were tested with comparisons of the FMS CS and 1RM squat with ten and twenty meter sprints, vertical jump, T test completion time and club head swing velocity. ${ }^{15,16,65}$ The researchers discovered that FMS CS and individual movement scores did not have a significant correlation to athletic performance results. ${ }^{15,16}$ On the contrary, the 1RM displayed a strong correlation to athletic performance. ${ }^{15,16,65}$ The 1RM most likely served as a better predictor of these performance tests since there was involvement of muscular power and strength. The club head swing velocity, a sport specific measure, helps make the performance testing sport-specific to golfers. ${ }^{15,16}$ It is imperative to acknowledge that a component of athletic performance is strength. The FMS movements assess strength, along with mobility and stability. ${ }^{7-11}$.

Balance and stability are important components of functional movement. ${ }^{56}$ Sports such as gymnastics, skateboarding and figure skating emphasize balance as an important part of performance. Asymmetries and limitations could result in poor balance. The Balance Error Scoring System (BESS) and Y Balance Test (YBT) could be used to assess balance and compare this score with the FMS CS. ${ }^{57,58}$ Motte $^{68}$ evaluated 1714 military applicants with the FMS and compared the scores of the Landing Error Score System (LESS) and YBT. Only a moderate 
association between FMS, LESS, and YBT was found among females. ${ }^{66}$ Balance will be necessary, but does not encompass all the physical demands that will be tested during basic training. Future research can focus on establishing performance testing protocols to establish consistency when determining if the FMS can predict athletic performance for specific active populations.

Including participants without existing injuries and refraining participants from physical activity for twenty-four hours prior to testing can help to validate the FMS to predict athletic performance. ${ }^{15,16}$ Injury and soreness can negatively influence the ability to execute performance and FMS movements. ${ }^{15,16}$ By eliminating these factors, there is more consistency among athletes. The 10 and 20 meter sprints, vertical jump and $\mathrm{T}$ test completion time are performance assessments that are applicable to numerous forms of physical activity. ${ }^{15,16}$

Validity of The FMS to assess risk and prediction of the effectiveness of training or intervention programs, injury, and athletic performance needs further investigation. ${ }^{69-74}$ Prediction of injury and athletic performance goes outside the scope and purpose of the FMS. Collectively, these new implementations lack validity. The new implementations appear to have a similar meaning from the FMS original purpose. Skilled clinicians such as athletic trainers, physical therapists and strength and conditioning coaches need to think critically about the purpose of the FMS before they implement into practice. The goal of the clinician should match the goal of the screen. ${ }^{69-74}$ Overall, it is difficult to measure the validity of the FMS since there is no gold standard for functional movement screening. Assessing the validity of the FMS against a gold standard could serve as a better testament to the screening tool's ability to assess for musculoskeletal asymmetries and limitations present in functional movement. Functional Movement Screen Composite Scores In Field Sports 
The FMS is gaining recognition and being implemented across high school, collegiate and professional sports along with military personnel, police officers and firefighters. Reviewing FMS studies on high school, collegiate, and professional athletes demonstrated the need to examine different active populations. Copious students enrolled at a college or university across the United States have the opportunity to participate in a club sport. Collegiate club sport athletes spend numerous hours training and competing. In particular, athletes participating in field sports are at risk for movement deficiencies as a result of musculoskeletal asymmetries and limitations. Rugby and soccer athletes have been examined at various competition levels except club sports. Youth male soccer players at elite English academies have access to physiotherapists, sports scientist, and strength and conditioning coaches ${ }^{67}$ These athletes completed the FMS and other screening tools. ${ }^{67}$ Lacrosse athletes have yet to be investigated in the literature.

One study assessed 1,005 adolescent school children in India. ${ }^{77}$ The mean FMS CS was $14.59 \pm 2.48 .{ }^{59}$ Using 2,475 physically active male soldiers, non-injured soldiers scored higher than soldiers who had an overuse, traumatic, or any other injury $(16.3 \pm 2.3$ vs. $15.0 \pm 3.1$, $15.6 \pm 2.8,15.2 \pm 3.0) .{ }^{65}, 66$ In another study, twenty-two male recreational team sport athletes participating in soccer, basketball, rugby league, rugby union, Australian football, or touch football were assessed. ${ }^{15,16}$ The mean FMS CS equated to $15.09 \pm 2.18 .{ }^{15,16}$ In contrast, 62 South African professional rugby union players completed the FMS to compare CS between injured and non-injured athletes. ${ }^{17}$ The FMS CS was $13.2 \pm 1.7$ vs. $14.5 \pm 1.5$, which is lower than the Lockie $^{15,16}$ study. Seventy-six male union rugby players completed the FMS at the beginning of each half of a season. An insignificant difference in FMS CS were noted between the first and second half of the season, $15.2 \pm 1.94$ vs. $15.4 \pm 2.05 .{ }^{18}$ Twenty-three U16 and twenty-five U19 youth elite soccer players completed the FMS. ${ }^{21}$ Functional movement scores were $13.87 \pm 2.93$ 
vs. 14.96 $+2.07 .{ }^{21}$ Negligible differences were noted within individual FMS movements between the two age groups. ${ }^{21}$ A comparison between NCAA Division II men's and women's soccer players was conducted to assess differences in FMS CS. ${ }^{19}$ Men's soccer scored slightly higher than women's soccer, 16.16+1.54 vs. 15.78+1.85. ${ }^{19,67}$ Forty-seven Division II men's and women's soccer players averaged a 15.84_1.73 FMS CS. ${ }^{20}$ Sixty-two Division I women's soccer players had an average FMS CS of $14 .^{22}$

An examination of these studies suggested that injury and younger ages negatively impact FMS CS in field sport athletes. It can be inferred that a contact sport, such a rugby, can result in lower FMS CS. Collegiate soccer players may have displayed higher scores than elite youth players due to availability of a sports medicine and strength and conditioning staff, developed neuromuscular control, and matured musculoskeletal system. ${ }^{68}$ Thirty male youth soccer players from three different age groups were assessed with the FMS, the maximal rebounding test, and reactive agility. ${ }^{70}$ The under sixteen group performed better than the under thirteen and eleven groups in all assessments. ${ }^{70}$ FMS CS were 16.0+2.0, 12.5+3.0, and 12.0+1.5 respectively. ${ }^{70}$ An elite group of Gaelic Football and Hurling athletes scored higher than a SubElite group on the FMS $(15.8 \pm 1.58$ vs $15.34+1.31) .{ }^{78} 200$ young, active males and females that were healthy and free from injury earned an average FMS CS of $15.7{ }^{68}$ Further research is needed to understand how field club sport athletes, such as rugby, soccer, and lacrosse, will score on the FMS. Each competition level has different time commitments, intensities, and availability of resources that can impact the score. Thus, field club sport athletes must be studied to identify individual areas of concern that may not correlate with other competition levels.

Summary 
Despite the rapid growth of collegiate club sports, there is no nationally governing body. Collegiate club sport athletes do not receive the same level of care or accessibility to resources compared to varsity athletes. Collegiate field club sports have not been thoroughly discussed in the literature. Rugby, soccer and lacrosse club sport athletes experience deficient movement patterns as a result of intense training and competition. The current literature displays significant injury rates across these sports. The FMS is a screening tool to assess musculoskeletal asymmetries and limitations so an individualized movement profile and intervention can be developed. The FMS includes the: deep squat, inline lunge, hurdle step, shoulder mobility, active straight leg raise, trunk stability push-up, and quadruped rotatory stability. Reliability of the FMS varies from moderate to strong across expert and novice raters. There is insufficient data on validity because most studies focus on injury risk or performance. The validity of the FMS should assess musculoskeletal asymmetries and limitations in functional movement patterns. Field club sport athletes demonstrate FMS CS around 14, the cut-off. Attention to functional movement patterns is necessary to provide individualized, corrective interventions. 


\section{APPENDIX C}

\section{ADDITIONAL METHODS}

Table C1. Consent Information and HIPAA Form

Principal Investigator

Department

Protocol Number

Study Title

Co-Investigator(s)
Only Minimal Risk

Consent Information and HIPAA Form

Michelle Sandrey, PhD, ATC

College of Physical Activity and Sport Sciences

1712881058

Functional Movement Screen Composite Scores For Collegiate

Field Club Sport Athletes at One University

Daniel Camillone, ATC

\section{Contact Persons}

In the event you experience any side effects or injury related to this research, you should contact Principal Investigator Dr. Michelle A. Sandrey, PhD, ATC at (304) 293-0870 or at msandrey@mail.wvu.edu or Daniel Camillone, ATC at (914) 483-8967 or at dac0022@mix.wvu.edu. If you have any questions, concerns, or complaints about this research, you can contact PI Dr. Michelle A. Sandrey, PhD, ATC at (304) 293-0870 or at msandrey@mail.wvu.edu or Daniel Camillone, ATC at (914) 483-8967 or at dac0022@mix.wvu.edu.

For information regarding your rights as a research subject, to discuss problems, concerns, or suggestions related to the research, to obtain information or offer input about the research, contact the Office of Research Integrity and Compliance at (304) 293-7073.

In addition if you would like to discuss problems, concerns, have suggestions related to research, or would like to offer input about the research, contact the Office of Research Integrity and Compliance at 304-293-7073.

\section{Introduction}

You, , have been asked to participate in this research study, which has been explained to you by . This study is being conducted by Principal Investigator, Michelle A. Sandrey, PhD, ATC and Co- investigator, Daniel Camillone, ATC in the Department of College of Physical Activity and Sport Sciences at West Virginia University. This research is being conducted to fulfill the requirements for a Thesis in the College of Physical Activity and Sport Sciences at West Virginia University under the supervision of Michelle A. Sandrey, PhD, ATC.

\section{Purpose(s) of the Study}

The purpose of this study is to determine how collegiate field club sport athletes score on the Functional Movement Screen. 


\section{Description of Procedures}

You will be asked to complete a demographic questionnaire (including age, sport, time spent performing physical activity per week, number of years of participation in the sport, foot type, and orthotic use) as well as to determine eligibility to participate in this study. This will take approximately five to ten minutes to complete. You do not have to answer all the questions. You will have the opportunity to see the questionnaire before signing this consent form. All completed forms will be kept confidential. If you are an eligible subject, you will be asked to participate in one session. Testing will occur on the dates and times given to you by the coinvestigator.

Functional Movement Screen

Functional Movement Screening is an assessment of functional movement completed over seven different fundamental movements, which include dynamic stability, static stability, and mobility. For this screening, you will have a demonstration period and a testing period for each section. You will complete each section for a maximum of three trials. There will be approximately ten to twenty seconds of rest between trials. The seven movements you will complete are the Deep Squat, Hurdle Step, Incline Lunge, Shoulder Mobility, Active Straight Leg Raise, Trunk Stability Push Up, and Rotary Stability. This will take approximately twenty minutes to complete.

-Deep Squat: You will be holding a dowel overhead and attempt to squat parallel while keeping your heels on the ground. • Hurdle Step: You will hold a dowel behind your head resting on top of your shoulders. You will step over the hurdle touching your heel to the ground. Then you will return your heel to the start position. -Inline Lunge: You will hold the dowel in line with your back. You will lunge forward, touching your knee to the ground.

-Shoulder Mobility: You will put one hand overhead and the opposite hand behind your back, trying to make contact. The shoulder clearing test will involve you placing one hand to the opposite shoulder without pain. -Active Straight Leg Raise: You will lie on your back and raise one leg. The opposite leg and back must stay on the ground.

-Trunk Stability Push-Up: You will lie on your stomach with your hands lined up to your chin. The spinal extension clearing test will involve you placing your hands under your shoulders, trying to extend your elbows. - Rotary Stability: You will be on your hands and knees. You will extend your arm and leg on the same side. You will attempt to touch the same elbow and knee. The spinal flexion clearing test involves you sitting back on your heels while extending the arms out as far as possible.

\section{Discomforts}

There are no known or expected risks to you from participating in this study. A feeling of discomfort and soreness from completing the measurements may be felt and this will be no more than what is felt when learning a new exercise or skill. If an injury occurs during the study, Daniel Camillone, ATC will provide the necessary first aid and referral if necessary. If warranted, a referral will be your responsibility.

\section{Alternatives}

You do not have to participate in this study. You may withdraw at any time with no penalty. 


\section{Benefits}

You may not receive any direct benefit from this study. The knowledge gained from this study may eventually benefit others by determining where collegiate field club sport athletes experience movement deficiency.

\section{Financial Considerations}

There will be no payments made for participation in this study. There are no costs to participants in this study. No extra credit will be received for participation.

\section{Confidentiality}

Any information about you that is obtained as a result of your participation in this research will be kept as confidential as legally possible. Your research records and test results, just like hospital records, may be subpoenaed by court order or may be inspected by the study sponsor or federal regulatory authorities without your additional consent.

In any publications that result from this research, neither your name nor any information from which you might be identified will be published without your consent.

\section{HIPAA}

We know that information about you and your health is private. We are dedicated to protecting the privacy of that information. Because of this promise, we must get your written authorization (permission) before we may use or disclose your protected health information or share it with others for research purposes.

You can decide to sign or not to sign this authorization section. However, if you choose not to sign this authorization, you will not be able to take part in the research study. Whatever choice you make about this research study will not have an effect on your access to medical care.

You can decide to sign or not to sign this authorization section. However, if you choose not to sign this authorization, you will not be able to take part in the research study. Whatever choice you make about this research study will not have an effect on your access to medical care.

\section{Persons/Organizations Providing the Information}

Members of the West Virginia University's Field Club Sports.

\section{Persons/Organizations Receiving the Information}

- Health care providers who provide services to you as part of this research study: WVU, Michelle A. Sandrey, PhD, ATC, Daniel Camillone ATC. The research site(s) carrying out this study includes WVU. 
- The United State Department of Health and Human Services (which includes the National Institutes of Health (NIH), Food and Drug Administration (FDA)) and other groups that have the right to use the information as required by law.

- The members and staff of any Institutional Review Board (IRB) that oversees this research study.

- West Virginia University Office of Research Integrity and Compliance and Office of Sponsored Programs.

\section{The Following Information Will Be Used}

Information from you and new information about you that is created or collected during the study such as: injury history, demographics, level of physical activity, Functional Movement Screen scores, and study forms.

\section{The Information is Being Disclosed for the Following Reasons}

- Review of your data for quality assurance purposes.

-Publication of study results (without identifying you)

You May Cancel this Authorization at Any Time by Writing to the Principal Investigator Michelle A Sandrey, PO Box 6116, West Virginia University, Morgantown,WV 26506-6116

If you cancel this authorization, any information that was collected already for this study cannot be withdrawn. Once information is disclosed, according to this authorization, the recipient may redisclose it and then the information may no longer be protected by federal regulations.

You have a right to see and make copies of your medical records. You will not be able to see or copy your records related to the study until the sponsor has completed all work related to the study. At that time you may ask to see the study files related to your participation in the study and have the co-PI correct any information about you that is wrong.

This authorization will expire at the end of the study unless you cancel it before that time.

\section{Voluntary Participation}

Participation in this study is voluntary. You are free to withdraw your consent to participate in this study at any time.

Refusal to participate or withdrawal will not affect your willingness to participate and will involve no penalty to you. Refusal to participate or withdrawal will not affect your future care of injuries or eligibility to play club sports at West Virginia University. 
In the event new information becomes available that may affect your willingness to participate in this study, this information will be given to you so that you can make an informed decision about whether or not to continue your participation.

You have been given the opportunity to ask questions about the research, and you have received answers concerning areas you did not understand.

Upon signing this form, you will receive a copy.

I willingly consent to participate in this research.

\section{Signatures}

Signature of Subject

\begin{tabular}{lll}
\hline Printed Name & Date & Time
\end{tabular}

The participant has had the opportunity to have questions addressed. The participant willingly agrees to be in the study.

Signature of Investigator or Co-Investigator

\begin{tabular}{lll}
\hline Printed Name & Date & Time
\end{tabular}


Subject Number:

Age:

Height: Weight:

Sport: Sex: (circle one) Male / Female

Year in School: (circle one) Freshman / Sophomore / Junior / Senior / Other

Years participated in your sport: (circle one) $\geq 10$ years $/<10$ years of participation

Hours spent practicing, training and competing per week: (circle one) $\geq 12$ hours $/<12$ hours

Have been previously informed of or diagnosed with one of the following: (circle one)

Pronated (flat feet) / Supinated (high arches)

Do you currently wear orthotics or insoles: (circle one) Yes / No

Have you had an injury in the past twelve months that has required medical intervention?

1. Body Part Injured:

What happened?

Diagnosis:

Is this an ongoing injury? If so, please explain why.

2. Body Part Injured:

What happened?

Diagnosis:

Is this an ongoing injury? If so, please explain why.

Are you currently managing other injuries that would affect your ability to participate in this research? If yes, please explain. 
Table C3. Verbal Instructions for the Functional Movement Screen ${ }^{7-11}$

\section{VERBAL INSTRUCTIONS FOR THE FUNCTIONAL MOVEMENT SCREEN}

The following information is a script to follow while administering the FMS. For consistency throughout all screens, the script should be used during each screen. The bold words represent what you should say to the client.

Please let me know if there is any pain while performing any of the following movements.

DEEP SQUAT

EQUIPMENT NEEDED: DOWEL, 2 X 6

INSTRUCTIONS:

- Stand tall with your feet approximately shoulder width apart and toes pointing forward.

- Grasp the dowel with both hands and place it horizontally on top of your head so your shoulders and elbows are at 90 degrees.

- Press the dowel so that is it directly above your head.

- While maintaining an upright torso, and keep your heels and dowel in position, descend as deep as possible.

- Hold the descend position for a count of one, then return to the starting position.

- Do you understand the instructions?

Score the movement.

The client can perform the move up to three times total if necessary.

If a score is not achieved, repeat the above instructions using the $2 \times 6$ under the client's heels.

HURDLE STEP

\section{EQUIPMENT NEEDED: DOWEL, HURDLE}

INSTRUCTIONS:

- Stand tall with your feet together and toes touching the test kit.

- Grasp the dowel with both hands and placer it behind your neck and across the shoulders.

- While maintaining an upright posture, raise the right leg and step over the hurdle, making sure to raise the foot towards the shin and maintaining foot alignment with the ankle, knee and hip.

- Touch the floor with the heel and return to the starting position while maintaining foot alignment with the ankle, knee and hip.

- Do you understand these instructions?

Score the moving leg.

Repeat the test on the other side.

Repeat two times per side if necessary.

INLINE LUNGE

EQUIPMENT NEEDED: DOWEL, 2 X 6

INSTRUCTIONS 
- Place the dowel along the spine so it touches the back of your head, your upper back and the middle of the buttocks.

- While grasping the dowel, your right hand should be against the back of your neck, and the left hand should be against your lower back.

- Step onto the $2 \times 6$ with a flat right foot and your toe on the zero mark.

- The left heel should be placed at mark. This the tibial measurement marker.

- Both toes must be pointing forward, with flat feet.

- Maintaining an upright posture so the dowel stays in contact with your head, upper back and top of buttocks, descend into a lunge position so the right knee touches the $2 \times 6$ behind your left heel.

- Return to the starting position.

- Do you understand these instructions?

Score the movement.

Repeat the test on the other side.

Repeat two times per side if necessary.

SHOULDER MOBILITY

\section{EQUIPMENT NEEDED: MEASURING DEVICE}

\section{INSTRUCTIONS}

- Stand tall with your feet together and arms hanging comfortably.

- Make a fist so your fingers are around your thumbs.

- In one motion, place the right fist over head and down your back as far as possible while simultaneously taking your let fist up your back as far as possible.

- Do not "creep" your hands closer after their initial placement.

- Do you understand these instructions?

Measure the distance between the two closest points of each fist.

Score the movement.

Repeat the test on the other side.

\section{ACTIVE SCAPULAR STABILITY (SHOULDER CLEARING)}

\section{INSTRUCTIONS}

- Stand tall with your feet together and arms hanging comfortably.

- Place your right palm on the front of your left shoulder.

- While maintaining palm placement, raise your right elbow as high as possible.

- Do you feel any pain?

Repeat the test on the other side.

ACTIVE STRAIGHT-LEG RAISE

EQUIPMENT NEEDED: DOWEL, MEASURING DEVICE, 2 X 6

INSTRUCTIONS

- Lay flat with the back of your knees against the $2 \times 6$ with your toes pointing up.

- Place both arms next to your body with the palms facing up.

- Pull the toes of your right foot toward your shin. 
- With the right leg remaining straight and the back fo your left knee maintaining contact with the $2 \times 6$, raise your right foot as high as possible.

- Do you understand these instructions?

Score the movement.

Repeat the test on the other side.

TRUNK STABILITY PUSH UP

EQUIPMENT NEEDED: NONE

INSTRUCTIONS:

- Lie face down with your arms extended overhead and your hands shoulder width apart.

- Pull your thumbs down in line with the (forehead for men, chin for women).

- With your legs together, pull your toes toward the shins and lift your knees and elbows off the ground.

- While maintaining a rigid torso, push your body as one unit into a pushup position.

- Do you understand these instructions?

Score the movement.

Repeat the test on the other side.

SPINAL EXTENSION CLEARING

EQUIPMENT NEEDED: NONE

INSTRUCTIONS:

- While lying on your stomach, place your hands, palms down, under your shoulders.

- With no lower body movement, press your chest off the surface as much as possible by straightening your elbows.

- Do you understand these instructions?

- Do you have any pain?

ROTARY STABILITY

EQUIPMENT NEEDED: 2 X 6

INSTRUCTIONS:

- Get on your hands and knees over the $2 \times 6$ so your hands are under your shoulders and your knees are under your hips.

- The thumbs, knees and toes must contact the sides of the $2 \times 6$, and the toes must be pulled toward the shins.

- At the same time, reach your right hand forward and right leg backward like you are flying.

- Then without touching down, touch your right elbow to your right knee directly over the $2 \times 6$.

- Return to the extended position.

- Return to the start position.

- Do you understand these instructions?

Score the movement.

Repeat the test on the other side.

If necessary, instruct the client to use a diagonal pattern of right arm and left leg. 
Repeat the diagonal pattern with left arm and right leg.

Score the movement.

INSTRUCTIONS:

- Get on all fours, and rock your hips toward your heels.

- Lower your chest to your knees, and reach your hands in front of your body as far as possible.

- Do you understand these instructions?

- Do you feel any pain? 


\section{FUNCTIONAL MOVEMENT SCREEN}

Score

Criteria

\section{Illustration}

\section{Deep Squat}

3

2

1

0

Pain during test vertical vertical

- Upper torso is parallel with tibia or toward

- Femur below horizontal

- Knees are aligned over feet

- Dowel aligned over feet

Performed with heels on $2 \times 6$ in board

- Upper torso is parallel with tibia or toward

- Femur below horizontal

- Knees are aligned over feet

- Dowel aligned over feet

Performed with heel on $2 \times 6$ in board

- If any of the 4 criteria are not met when the squat is performed with heels on $2 \times 6$ in board, the score is a 1
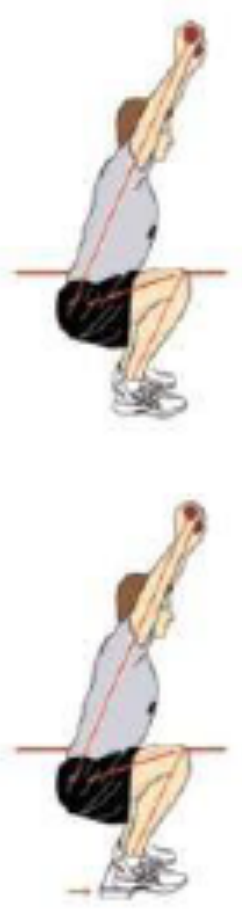

Hurdle step (test right and left)*

3

- Foot clears cord (does not touch) and remains dorsiflexed as leg is lifted over hurdle

- Hips, knees, and ankles remain aligned in the sagittal plane

- Minimal to no movement is noted in lumbar spine

- Dowel and hurdle remain parallel

2

- Alignment is lost between hips, knees, and ankles

- Movement is noted in lumbar spine

- Dowel and hurdle do not remain parallel 
- Contact between foot and hurdle

- Loss of balance

0

- Pain during test

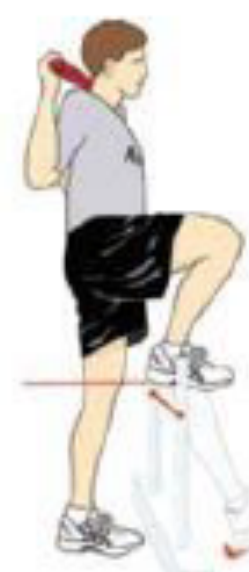

In-line Lunge (test right and left)*

3

- Knee touches board behind heel

- Dowel and feet remain in sagittal plane

- Dowel contacts remain (head, thoracic spine, sacrum)

- Dowel remains vertical, no torso movement noted

2

- Knee does not touch behind heel

- Dowel and feet do not remain in sagittal plane

- Dowel contacts do not remain

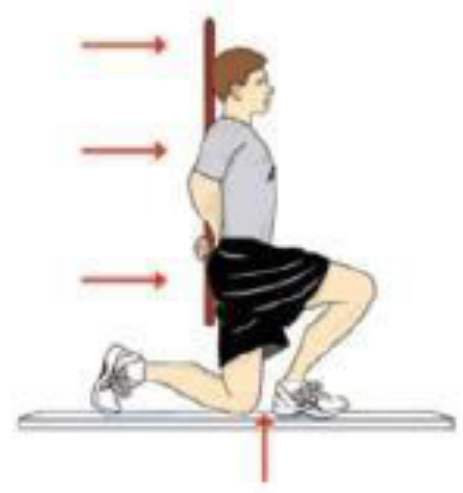

- Dowel remains vertical

- Movement noted in torso

1

- Loss of balance

- Inability to achieve start position

- Inability to touch knee to board

0

- Pain during test

\section{Active Straight Leg Raise (test right and left)*}

3

- Malleolus of tested lower extremity located in the region between mid-thigh and anterior superior iliac spine of opposite lower extremity

- Opposite hip remains neutral (hip does not externally rotate), toes remain pointed up

- Opposite knee remains in contact with board 
- Malleolus of tested lower extremity located in the region between mid-thigh and knee joint line of opposite lower extremity while other criteria are met

- Malleolus of tested lower extremity located in the region below knee joint line of opposite lower extremity, while other criteria are met

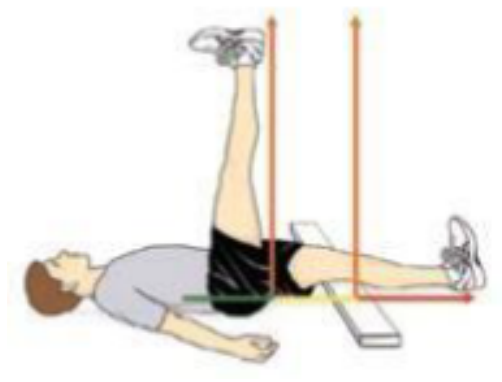

0

- Pain during test

\section{Shoulder Mobility (test right and left)*}

3

2

1

0
- Fists are within 1 hand length

- Fists are within 1.5 hand lengths

- Fists are not within 1.5 hand lengths

- Pain during test

\section{Shoulder Mobility Clearing Test}

If pain is noted as elbow is lifted, shoulder mobility is scored as 0

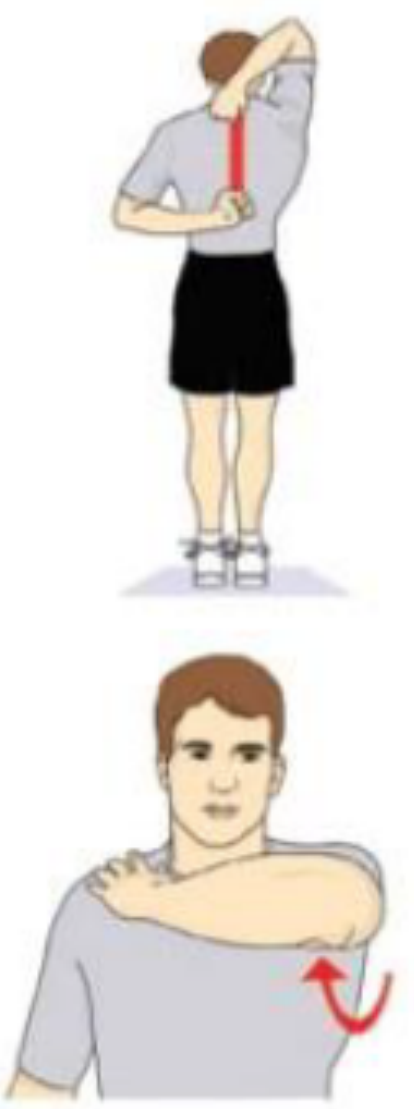

\section{Trunk Stability Push-Up}

3

- Perform 1 rep: thumbs are aligned with forehead for males and chin for females

- Body is lifted as 1 unit (no sag in lumbar spine) 
- Perform 1 rep: thumbs are aligned with chin for males and clavicle for females

- Unable to perform 1 repetition with thumbs aligned with chin for males and clavicle for females

0

- Pain during test

\section{Extension Clearing Test}

If pain is noted during a prone press-up, push-up is scored as 0 .
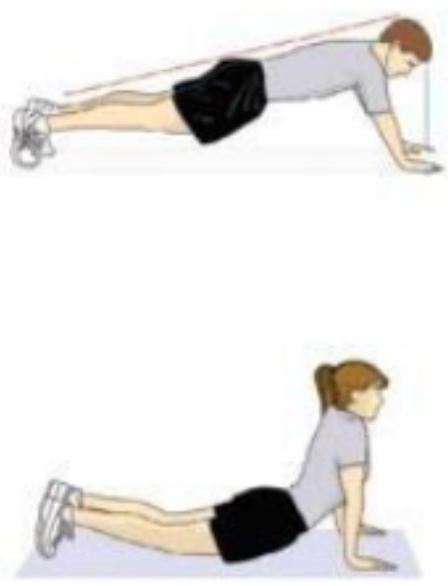

\section{Quadruped Rotary Stability (test right and left)*}

3

- 1 unilateral repetition (lift arm and left from same side)

- Keep spine parallel to board

- Knee and elbow touch in line over the board and then return to the start position

2

- 1 unilateral repetition (lift arm and leg from opposite side)

- Keep spine parallel to board

- Knee and elbow touch in line over the board and then return to the start position

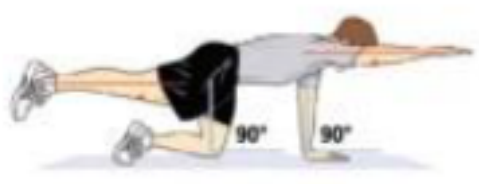$$
\text { Inability to perform diagonal repetition }
$$

- Pain during test

\section{Flexion Clearing Test}

If pain is noted during quadruped flexion, rotary stability is scored a 0

*Tests that are scored for both right and left sides, the lower score is used when calculating FMS composite scores. 
Table C5. Functional Movement Screen Scoring Sheet

\section{THE FUNCTIONAL MOVEMENT SCREEN SCORING SHEET}

Subject Number

Date

Hand/Leg Dominance

School

\begin{tabular}{llll}
\hline Height & Weight & Age & Sex \\
\hline Sport & Position & & \\
\hline
\end{tabular}

\begin{tabular}{|c|c|c|c|c|}
\hline \multicolumn{2}{|l|}{ TEST } & RAW SCORE & \multirow[t]{2}{*}{ FINAL SCORE } & \multirow[t]{2}{*}{ COMMENTS } \\
\hline \multicolumn{2}{|l|}{ Deep Squat } & & & \\
\hline \multirow[t]{2}{*}{ Hurdle Step } & $\mathrm{L}$ & & & \\
\hline & $\mathrm{R}$ & & & \\
\hline \multirow[t]{2}{*}{ Inline Lunge } & $\mathrm{L}$ & & & \\
\hline & $\mathrm{R}$ & & & \\
\hline \multirow[t]{2}{*}{ Shoulder Mobility } & $\mathrm{L}$ & & & \\
\hline & $\mathrm{R}$ & & & \\
\hline \multirow[t]{2}{*}{ Impingement Clearing Test } & $\mathrm{L}$ & & & \\
\hline & $\mathrm{R}$ & & & \\
\hline \multirow[t]{2}{*}{ Active Straight Leg Raise } & $\mathrm{L}$ & & & \\
\hline & $\mathrm{R}$ & & & \\
\hline \multicolumn{2}{|l|}{ Trunk Stability Push Up } & & & \\
\hline \multicolumn{2}{|l|}{ Press Up Clearing Test } & & & \\
\hline \multirow[t]{2}{*}{ Rotary Stability } & $\mathrm{L}$ & & & \\
\hline & $\mathrm{R}$ & & & \\
\hline \multicolumn{2}{|c|}{ Posterior Rocking Clearing Test } & & & \\
\hline
\end{tabular}


TOTAL

RAW SCORE: This score is used to denote right and left side scoring. The right and left sides are scored in five of the seven tests and both are documented in this space.

FINAL SCORE: This score is used to denote the overall score for the test. The lowest score for the raw score (each side) is carried over to give a final score for the test. A person who scores a three on the right and a two on the left would receive a score of 2 . The final score is then summarized and uses a total score. 


\section{APPENDIX D}

\section{ADDITIONAL RESULTS}

Table D1. Frequency and Mean For FMS CS and Individual Movements

\begin{tabular}{lllllllll}
\hline Sport & CS & DS & HS & IL & SM & ASLR & TSPU & RS \\
\hline Total (n=31) & $15.1 \pm 1.49$ & $1.971 \pm 0.31$ & $2.091 \pm 0.40$ & $2.481 \pm 0.57$ & $1.91 \pm 0.83$ & $2.651 \pm 0.55$ & $2.031 \pm 0.66$ & $2.0 \pm 0.0$ \\
Women's Soccer & $14.9 \pm 1.44$ & $2(\mathrm{n}=12)$, & $2(\mathrm{n}=11)$, & $2(\mathrm{n}=6)$, & $2(\mathrm{n}=6)$, & $3(\mathrm{n}=8)$, & $2(\mathrm{n}=10)$, & $2(\mathrm{n}=14)$, \\
(n=14) & & $1.86 \pm 0.36$ & $2.07 \pm 0.47$ & $2.57 \pm 0.51$ & $2.0 \pm 0.78$ & $2.5 \pm 0.65$ & $1.92 \pm 0.73$ & $2.0 \pm 0.0$ \\
Men's Soccer & $15.0 \pm 0.0$ & $2(\mathrm{n}=1)$, & $2(\mathrm{n}=1)$, & $3(\mathrm{n}=1)$, & $2(\mathrm{n}=1)$, & $2(\mathrm{n}=1)$, & $2(\mathrm{n}=1)$, & $2(\mathrm{n}=1)$, \\
(n=1) & & $2.0 \pm 0.0$ & $2.0 \pm 0.0$ & $3.0 \pm 0.0$ & $2.0 \pm 0.0$ & $2.0 \pm 0.0$ & $2.0 \pm 0.0$ & $2.0 \pm 0.0$ \\
Women's Rugby & $14.5 \pm 1.29$ & $2(\mathrm{n}=4)$, & $2(\mathrm{n}=3)$, & $2,3(\mathrm{n}=4)$, & $1,2(\mathrm{n}=4)$, & $3(\mathrm{n}=4)$, & $1,2(\mathrm{n}=4)$, & $2(\mathrm{n}=4)$, \\
(n=4) & & $2.0 \pm 0.0$ & $2.25 \pm 0.5$ & $2.5 \pm 0.58$ & $1.5 \pm 0.58$ & $3.0 \pm 0.0$ & $1.5 \pm 0.58$ & $2.0 \pm 0.0$ \\
Men's Rugby & $15.3 \pm 2.05$ & $2(\mathrm{n}=7)$, & $2(\mathrm{n}=8)$, & $4(\mathrm{n}=2)$, & $1,3(\mathrm{n}=6)$, & $3(\mathrm{n}=5)$, & $2,3(\mathrm{n}=8)$, & $2(\mathrm{n}=8)$, \\
(n=8) & & $2.13 \pm 0.35$ & $2.0 \pm 0.0$ & $2.25 \pm 0.71$ & $1.75 \pm 1.16$ & $2.63 \pm 0.52$ & $2.5 \pm 0.53$ & $2.0 \pm 0.0$ \\
Women's Lacrosse & $16.0 \pm 0.0$ & $2(\mathrm{n}=3)$, & $2(\mathrm{n}=3)$, & $2,3(\mathrm{n}=4)$, & $32(\mathrm{n}=3)$, & $3(\mathrm{n}=4)$, & $2(\mathrm{n}=4)$, & $2(\mathrm{n}=4)$, \\
(n=4) & & $2.0 \pm 0.0$ & $2.25 \pm 0.5$ & $2.5 \pm 0.58$ & $2.25 \pm 0.5$ & $3.0 \pm 0.0$ & $2.0 \pm 0.0$ & $2.0 \pm 0.0$ \\
\hline
\end{tabular}

Table D2. Descriptive Statistics and ANOVA for Year in Sport

\begin{tabular}{|c|c|c|c|c|c|c|c|c|}
\hline & FMS CS & DS & HS & IL & $\mathrm{SM}$ & ASLR & TSPU & $\mathrm{RS}$ \\
\hline $\begin{array}{l}\geq 10 \\
\text { years in } \\
\text { sport } \\
(n=17)\end{array}$ & $14.94 \pm 1.71$ & $2.0 \pm 0.35$ & $2.12 \pm 0.33$ & $2.47 \pm 0.62$ & $1.94 \pm 0.75$ & $52.65 \pm 0.4$ & $91.82 \pm 0.72$ & $2.0 \pm 0.0$ \\
\hline $\begin{array}{l}<10 \\
\text { years in } \\
\text { sport } \\
(n=14)\end{array}$ & $15.29 \pm 1.2$ & $1.93 \pm 0.27$ & $72.07 \pm 0.47$ & $2.5 \pm 0.52$ & $1.86 \pm 0.95$ & $52.64 \pm 0.63$ & $32.29 \pm 0.47$ & $2.0 \pm 0.0$ \\
\hline ANOVA & $\begin{array}{l}F=0.402 \\
p=0.531\end{array}$ & $\begin{array}{l}\mathrm{F}=0.388 \\
\mathrm{p}=0.538\end{array}$ & $\begin{array}{l}F=0.101, \\
p=0.753\end{array}$ & $\begin{array}{l}F=0.020 \\
p=0.889\end{array}$ & $\begin{array}{l}F=0.076 \\
p=0.785\end{array}$ & $\begin{array}{l}F=0.00 \\
p=0.984\end{array}$ & $\begin{array}{l}F=4.199 \\
p=0.050^{\wedge}\end{array}$ & * \\
\hline
\end{tabular}

Key: $*=$ Both scores were similar so there was no difference, ${ }^{\wedge}=$ significance at $\mathrm{P}=0.05$ 
Table D3. Descriptive Statistics and ANOVA for Hours per Week

\begin{tabular}{lllllllll}
\hline & CS & DS & HS & IL & SM & ASLR & TSPU & RS \\
\hline $\begin{array}{l}\geq 12 \\
\text { hours/week } \\
(\mathrm{n}=14)\end{array}$ & $15 \pm 1.36$ & $2.07 \pm 0.26$ & $2.0 \pm 0.39$ & $2.57 \pm 0.65$ & $1.79 \pm 0.8$ & $2.71 \pm 0.47$ & $1.93 \pm 0.62$ & $2.0 \pm 0.0$ \\
$<12$ & $15.17 \pm 1.63$ & $1.88 \pm 0.33$ & $2.17 \pm 0.39$ & $2.41 \pm 0.51$ & $2.0 \pm 0.87$ & $2.59 \pm 0.62$ & $2.11 \pm 0.7$ & $2.0 \pm 0.0$ \\
$\begin{array}{l}l \\
\text { hours/week }\end{array}$ & & & & & & & & \\
$\begin{array}{l}n=17) \\
\text { ANOVA }\end{array}$ & $\begin{array}{l}\mathrm{F}=.104, \\
\mathrm{p}=.104\end{array}$ & $\begin{array}{l}\mathrm{F}=2.967, \\
\mathrm{p}=0.096\end{array}$ & $\begin{array}{l}\mathrm{F}=1.55, \\
\mathrm{p}=0.223\end{array}$ & $\begin{array}{l}\mathrm{F}=0.595, \\
\mathrm{p}=0.447\end{array}$ & $\begin{array}{l}\mathrm{F}=0.502, \\
\mathrm{p}=0.484\end{array}$ & $\begin{array}{l}\mathrm{F}=0.394, \\
\mathrm{p}=0.535\end{array}$ & $\begin{array}{l}\mathrm{F}=0.627, \\
\mathrm{p}=0.435\end{array}$ & $*$ \\
\hline
\end{tabular}

Key: $*=$ Both scores were similar so there was no difference.

Table D4. Individual FMS Scores Related To Orthotics and Foot Type

\begin{tabular}{lllllll}
\hline & Frequency & Percent & CS & DS & HS & IL \\
\hline $\begin{array}{l}\text { Orthotics } \\
\text { (yes) }\end{array}$ & 3 & $9.7 \%$ & $14.0 \pm 0.0$ & $2.0 \pm 0.0$ & $2.0 \pm 0.0$ & $2.0 \pm 1.0$ \\
$\begin{array}{l}\text { Orthotics } \\
\text { (no) }\end{array}$ & 28 & $90.3 \%$ & $15.2 \pm 1.34$ & $1.96 \pm 0.33$ & $2.10 \pm 0.42$ & $2.54 \pm 0.51$ \\
Pes Planus & 1 & $3.2 \%$ & $15.0 \pm 0.0$ & $1 \pm 0.0$ & $2.0 \pm 0.0$ & $2.00 \pm 0.00$ \\
Pes Cavus & 7 & $22.6 \%$ & $14.7 \pm 1.98$ & $2.0 \pm 0.0$ & $2.29 \pm 0.49$ & $2.29 \pm 0.76$ \\
\hline
\end{tabular}




\section{APPENDIX E}

\section{RECOMMENDATIONS FOR FUTURE RESEARCH}

1. Collect data on FMS scores for all club sport athletes to establish significance, normative data, and generalizability for this population.

2. Ask subjects if they are currently wearing orthotics and to verify this during testing to provide a more accurate representation on how orthotic use effects FMS CS and individual movement scores.

3. Instructions provided by FMS do not state whether participants are required to wear shoes. Subjects should go through two rounds of screening, where the first screen is with shoes and the second a week later barefoot.

4. A new study should investigate indoor club sports athletes and compare the FMS CS and individual movement scores to field sports.

5. Future studies should focus on having pre-established relationships with teams, coaches, and players to have better cooperation from participants. This will help provide a more accurate representation of how years of participation and hours per week impact FMS CS and individual movement scores. 


\section{ADDITIONAL REFERENCES}

33. Dhillon H, Dhillon S, Dhillon MS. Current concepts in sports injury rehabilitation. Indian J Orthop. 2017;51(5):529-536.

34. Walker HL, Carr DJ, Chalmers DJ, Wilson CA. Injury to recreational and professional cricket players: circumstances, type and potential for intervention. AAP. 2010;42(6):20942098.

35. Willigenburg N, Hewett TE. Performance on the functional movement screen is related to hop performance but not to hip and knee strength in collegiate football players. Clin J Sport Med. 2017;27(2):119-126.

36. Warren M, Smith CA, Chimera NJ. Association of the functional movement screen with injuries in division I athletes. $J$ Sport Rehabil. 2015;24(2):163-170.

37. Breslin FC, Karmakar SD, Smith P, Etches J, Mustard C. Time allocation between work and recreation and the associated injury risks among young people. J Safety Res. 2007;38(3):373379.

38. Toth C. Peripheral nerve injuries attributable to sport and recreation. Neurol Clin. 2008;20(1):89-113.

39. McNoe BM, Chalmers DJ. Injury prevention behavior in community-level soccer players. $J$ Sci Med Sport. 2011;14(8):482-488.

40. Oliver GD, Adams-Blair HR. Improving core strength to prevent injury. $J$ Phys Ed Rec Dance. 2010;81(7):15-19.

41. Andrew NE, Wolfe R, Cameron P, Richardson M, Page R. Return to pre-injury health status and function 12 months after hospitalisation for sport and active recreation related orthopaedic injury. Inj Preven. 2012;18(6): 377-484.

42. Emerges CL, Gabbe BJ, Finch CF. Injury surveillance in community sport: can we obtain valid data from sports trainers? Scand J Med Sci Sports. 2015;25:315-322.

43. Andrew NE, Gabbe BJ, Wolfe R, Cameron PA. Evaluation of instruments for measuring the burden of sport and active recreation injury. Sports Med. 2010;40(2):141-161.

44. Andrew N, Wolfe R, Cameron P, Richardson M, Page R, Bucknill A, Gabbe B. The impact of sport and active recreation injuries on physical activity levels at 12 months post-injury. Scand J Med Sci Sports. 2014;24:377-385. 
45. Donaldson A, Borys D, Finch C, Middleton M. Developing an instrument to assess the sports injury risk management systems (sirms) of community sports club. Med Sci Sport Exerc. 2009;12:141.

46. Steinhagen MR, Meyers MC, Erickson HH et al. Physiological profile of college club-sport lacrosse athletes. J Strength Cond Res. 1998;12(4):226-231.

47. Pennington B. Rise of college club teams creates a whole new level of success. New York Times. 2008.

48. Chobra RS, Chobra DJ, Bouillon LE, Overmyer CA, Landus JA. Use of a functional movement screening tool to determine injury risk in female collegiate athletes. $N \mathrm{Am} J$ Sports Phys Ther. 2010;5(2):47-54.

49. Brigati, N. 2017-2018 Club sports manual. 2017. https://sites.psu.edu/clubsports/files/2014/06/Club-Sports-Manual-17-18-1dpuo27.pdf.

50. Yard EE, Schroeder MJ, Fields SK. The epidemiology of United States high school soccer injury, 2005-2007. Am J Sports Med. 2008;36(10):1930-1937.

51. Dick R, Lincoln AE, Agel J, Carter EA, Marshall SW, Hinton RY. Descriptive epidemiology of collegiate women's lacrosse injuries: national collegiate athletic association injury surveillance system, 1988-1989 through 2003-2004. J Athl Train. 2007;42(2):262-269.

52. Burggraf M, Heath EM, Fronske HA, et al. An overview of injuries and medical coverage for intramural and club sport at Utah State University. ProQuest Theses and Dissertations. 2004.

53. Levy AS, Wetzler MJ, Lewars M, Laughlin W. Knee injuries in women collegiate rugby players. Am J Sports Med. 1997;25(3):360-362.

54. Gnacinski SL, Cornell DJ, Meyer BB, Arvinen-Barrow M, Earl-Boehm JE. Functional movement screen factorial validity and measuremnt invariance across sex among collegiate student athletes. J Strength Cond Res. 2016;30(12):3388-3395.

55. Kiesel K, Plisky P, Butler R. Functional movement test scores improve following a standardized off-season intervention program in professional football players. Scand J Med Sci Sports. 2011;21:287-292.

56. Garrison M, Westrick R, Johnson MR et al. Association between the functional movement screen and injury development in college athletes. Int J Sports Phys Ther. 2015;10(1):21-28.

57. Ferreira Da Silva BA, Clemente FM, Lourenco Martins FM. Associations between functional movement screen scores and performance variables in surf athletes. J Sports Med Phys Fitness. 2017. 
58. Parenteau-G E, Gaudreault N, Chalmers $\mathrm{S}$ et al. Functional movement screen test: a reliable screening test for young elite ice hockey players. Phys There Sport. 2014;15(3):169-175.

59. Gulgin H, Hoogenboom B. The functional movement screening (fms) ${ }^{\mathrm{tm}}$ : an inter-rater reliability study between raters of varied experience. Int J Sports Phys Ther. 2014;9(1):1420.

60. Tafuri S, Notarnicola A, Monna A et al. Crossfit athletes exhibit high symmetry of fundamental movement patterns. A cross-sectional study. Muscles Ligaments Tendons J. 2016;6(1):157-160.

61. Okada T, Huxel KC, Nesser TW. Relationship between core stability, functional movement, and performance. J Strength Cond Res. 2011;25(1):252-261.

62. Olds KA, Butler S. Functional movement screen as a predictor of injury in an indistrial setting. USSA. 2016.

63. Shultz R, Anderson SC, Matheson GO et al. Test-retest and interrater reliability of the functional movement screen. J Athl Train. 2013;48(3):331-336.

64. Li Y, Wang X, Chen X et al. Exploratory factor analysis of the functional movement screen in elite athletes. J Sports Sci. 2015;33(11):1166-1172.

65. Koehle MS, Saffer BY, Sinnen NM et al. Factor structure and internal validity of the functional movement screen in adults. J Strength Cond Res. 30(2):540-556.

66. Schneiders AG, Davidsson A, Horman E et al. Functional movement screen normative values in a young, active population. Int J Sports Phys Ther. 2011;6(2):75-82.

67. Engquist KD, Smith CA, Chimera NJ et al. Performance comparison of student-athletes and general college students on the functional movement screen and y balance test. $J$ Strength Cond Res. 2015;29(8): 2296-2303.

68. de la Motte SJ, Gribbin TC, Lisman P et al. The interrelationship of common clinical movement screens: establishing population-specific norms in a large cohort of military applicants. J Athl Train. 2016;51(11):897-904.

69. Moran RW, Schneiders AG, Mason J et a. Do functional movement screen (fms) composite scores predict subsequent injury? a systematic review with meta-analysis. Br J Sports Med. 2017;51(23):1661-1669.

70. Read PJ, Jimenez P, Oliver Jl et al. Injury prevention in male youth soccer: current practices and perceptions of practitioners working at elite English academies. J Sport Sci.

2017;11(1):1-9. 
71. Bushman TT, Grier TL, Canham-Chervak M et al. The functional movement screen and injury risk: association and predictive value in active men. Am J Sports Med. 2016;44(2):297-304.

72. Lloyd RS, Oliver JL, Radnor JM et al. Relationships between functional movement screen scores, maturation and physical performance in young soccer players. J Sports Sci. 2015;33(1):11-19.

73. Bonazza NA, Smuin D, Onks CA, Silvis ML, Dhawan A. Reliability, validity, and injury predictive value of the functional movement screen: a systematic review and meta-analysis. Am J Sports Med. 2017;45(3):725-732.

74. Chimera NJ, Warren M. Use of clinical movement screening tests to predict injury in sport. World J Orthop. 2016;7(4):202-217.

75. Choi HS, Shin WS. Validity of the lower extremity functional movement screen in patients with chronic ankle instability. J Phys Ther Sci. 2015;27(6):1923-1927.

76. Chapman RD, Laymon AS, Arnold T. Functional movement scores and longitudinal performance outcomes in elite track athletes. Int J Sports Physiol Perform. 2014;9(2):203211.

77. Abraham A, Sannasi R, Nair R. Normative values for the functional movement screentm in adolescent school aged children. Int J Sports Phys Ther. 2015;10(1):29-36.

78. Fox D, O'Malley E, Blake C. Normative data for the functional movement screen in male gaelic field sports. Phys Ther Sport. 2014;15(3):194-199. 